\title{
Hydrogenated Amorphous Titania with Engineered Surface Oxygen Vacancy for Efficient Formaldehyde and Dye Removals under Visible-Light Irradiation
}

\author{
Guang Feng ${ }^{1,2}$, Mengyun $\mathrm{Hu}^{1,2,3}$, Botao $\mathrm{Wu}^{3}$, Shencheng Shi ${ }^{3}$, Shuai Yuan ${ }^{1,2}$, Yanan $\mathrm{Li}^{3}$ and Heping Zeng ${ }^{2,3, * \mathbb{C}}$ \\ 1 School of Optical-Electrical and Computer Engineering, University of Shanghai for Science and Technology, \\ Shanghai 200093, China; 191380035@st.usst.edu.cn (G.F.); myhu@phy.ecnu.edu.cn (M.H.); \\ syuan@usst.edu.cn (S.Y.) \\ 2 Chongqing Key Laboratory of Precision Optics, Chongqing Institute of East China Normal University, \\ Chongqing 401120, China \\ 3 State Key Laboratory of Precision Spectroscopy, East China Normal University, Shanghai 200062, China;

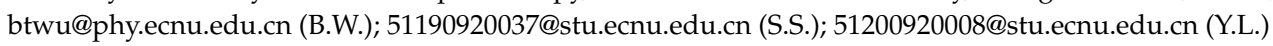 \\ * Correspondence: hpzeng@phy.ecnu.edu.cn
}

check for updates

Citation: Feng, G.; Hu, M.; Wu, B.; Shi, S.; Yuan, S.; Li, Y.; Zeng, H.

Hydrogenated Amorphous Titania with Engineered Surface Oxygen Vacancy for Efficient Formaldehyde and Dye Removals under

Visible-Light Irradiation.

Nanomaterials 2022, 12, 742. https:// doi.org/10.3390/nano12050742

Academic Editor: Francesc

Viñes Solana

Received: 5 January 2022

Accepted: 16 February 2022

Published: 22 February 2022

Publisher's Note: MDPI stays neutral with regard to jurisdictional claims in published maps and institutional affiliations.

Copyright: () 2022 by the authors Licensee MDPI, Basel, Switzerland. This article is an open access article distributed under the terms and conditions of the Creative Commons Attribution (CC BY) license (https:// creativecommons.org/licenses/by/ $4.0 /)$.

\begin{abstract}
Hydrogenated crystalized $\mathrm{TiO}_{2-\mathrm{x}}$ with oxygen vacant $\left(\mathrm{O}_{\mathrm{V}}\right)$ doping has attracted considerable attraction, owing to its impressive photoactivity. However, amorphous $\mathrm{TiO}_{2}$, as a common allotrope of titania, is ignored as a hydrogenated templet. In this work, hydrogenated amorphous $\mathrm{TiO}_{2-\mathrm{x}}\left(\mathrm{HAm}-\mathrm{TiO}_{2-\mathrm{x}}\right)$ with engineered surface $\mathrm{O}_{\mathrm{V}}$ and high surface area $\left(176.7 \mathrm{~cm}^{2} \mathrm{~g}^{-1}\right)$ was first prepared using a unique liquid plasma hydrogenation strategy. In $\mathrm{HAm}_{-} \mathrm{TiO}_{2-\mathrm{x}}$, we found that $\mathrm{O}_{\mathrm{V}}$ was energetically retained in the subsurface region; in particular, the subsurface $\mathrm{O}_{\mathrm{V}}$-induced energy level preferred to remain under the conduction band $(0.5 \mathrm{eV})$ to form a conduction band tail and deep trap states, resulting in a narrow bandgap $(2.36 \mathrm{eV})$. With the benefits of abundant light absorption and efficient photocarrier transportation, $\mathrm{HAm}-\mathrm{TiO}_{2-\mathrm{x}}$ coated glass has demonstrated superior visible-light-driven self-cleaning performances. To investigate its formaldehyde photodegradation under harsh indoor conditions, $\mathrm{HAm}-\mathrm{TiO}_{2-\mathrm{x}}$ was used to decompose low-concentration formaldehyde $(\sim 0.6 \mathrm{ppm})$ with weak-visible light $\left(\lambda=600 \mathrm{~nm}\right.$, power density $\left.=0.136 \mathrm{~mW} / \mathrm{cm}^{2}\right)$. Thus, $\mathrm{HAm}_{-} \mathrm{TiO}_{2-\mathrm{x}}$ achieved high quantum efficiency of $3 \times 10^{-6}$ molecules/photon and photoactivity of $92.6 \%$. The adsorption capabilities of $\mathrm{O}_{2}(-1.42 \mathrm{eV})$ and $\mathrm{HCHO}(-1.58 \mathrm{eV})$ in $\mathrm{HAm}^{-\mathrm{TiO}_{2-\mathrm{x}}}$ are both largely promoted in the presence of subsurface $\mathrm{O}_{\mathrm{V}}$. The surface reaction pathway and formaldehyde decomposition mechanism over $\mathrm{HAm}_{-} \mathrm{TiO}_{2-\mathrm{x}}$ were finally clarified. This work opened a promising way to fabricate hydrogenated amorphous photocatalysts, which could contribute to visible-light-driven photocatalytic environmental applications.
\end{abstract}

Keywords: amorphous $\mathrm{TiO}_{2}$; oxygen vacancy; bandgap; formaldehyde; visible light

\section{Introduction}

As a promising and environmentally-friend photocatalyst, titanium dioxide $\left(\mathrm{TiO}_{2}\right)$ has gained widespread traction in the past few decades [1-5]. In order to pursue the best performance in solar energy conversion and utilization, one of the most effective approaches in tuning the band structure and maximizing solar energy capture is $\mathrm{O}_{V}$ defect engineering of $\mathrm{TiO}_{2}$ [6-9]. Among considerable strategies in $\mathrm{O}_{\mathrm{V}}$ defect engineering, the most representative and effective one is thermal hydrogenation of crystallized $\mathrm{TiO}_{2}$, which promotes the generation of $\mathrm{O}_{\mathrm{V}}$-doped disordered surface at crystalline $\mathrm{TiO}_{2}$, i.e., a disordered surface at the crystalline core [9-12]. This unique configuration not only provides additional $\mathrm{O}_{\mathrm{V}}$-induced states to absorb long-wavelength light, thereby enabling colorful $\mathrm{TiO}_{2-x}$, but also encourages photoinduced charge separation to achieve superior visiblelight photoactivity [13-15]. To obtain photocatalysts with superior efficiency, the polymorph 
modifications of crystalline titanium dioxide also attracted much attention [16,17]. Alternatively, compared with crystalline $\mathrm{TiO}_{2}$, amorphous $\mathrm{TiO}_{2}$, which also exhibits an intrinsic narrow bandgap, thermodynamic metastability, and a large surface area, should be a great promising templet for surface hydrogenation [18-20]. Nevertheless, inherent drawbacks, including large quantities of bulk defects and inferior solar energy conversion eliminate this possibility. Theoretically, hydrogenated amorphous $\mathrm{TiO}_{2-x}\left(\mathrm{HAm}-\mathrm{TiO}_{2-\mathrm{x}}\right)$ ought to have a narrower bandgap and more surface- $\mathrm{O}_{\mathrm{V}}$-induced active sites, which are the crucial factors for high-visible photoactivity. However, in practice, thermal hydrogenation using amorphous $\mathrm{TiO}_{2}$ is ineluctable to require a long annealing process, which completely transforms the product into hydrogenated crystalline $\mathrm{TiO}_{2-\mathrm{x}}$ and easily erases the surface $\mathrm{O}_{\mathrm{V}}$. Given the above challenges in the synthesis theory and technology, hydrogenation of pure amorphous phase $\mathrm{TiO}_{2}$ has so far scarcely succeeded. Considering these aspects, the goal of this work is to prepare $\mathrm{HAm}_{-} \mathrm{TiO}_{2-\mathrm{x}}$ with an $\mathrm{O}_{\mathrm{V}}$-doped disordered surface (disordered surface at the amorphous core) and, particularly, to reveal the fundamental mechanism of the correlation between $\mathrm{O}_{\mathrm{V}}$ concentration and distribution, electrical structure, optical response, reactive oxygen species (ROS) generation, and its photoactivity, which can discover uncommon electrical and optical properties of $\mathrm{HAm}_{-} \mathrm{TiO}_{2-\mathrm{x}}$ better than traditional hydrogenated crystalline $\mathrm{TiO}_{2-x}$.

Formaldehyde, one of the most common indoor air pollutions, is highly poisonous and carcinogenic and is an immense threat to human health [21,22]. Photocatalytic formaldehyde purification is an efficient and safe method that can completely decompose formaldehyde into carbon dioxide and water [23-27]. Current studies on photocatalytic formaldehyde photodegradation are mainly focused on reaction mechanisms, such as peculiar formaldehyde physicochemical adsorption models and complex reaction pathways. In particular, they are focused on the synthesis of advanced photocatalysts with superior formaldehyde degradation performance under standard and ideal experimental conditions, including high power density of UV light source, high concentration formaldehyde, as well as high reaction temperature and pressure. However, in a practical indoor environment the situation is completely inverse: a practical indoor environment provides low-concentration formaldehyde (0.2-0.5 ppm), a weak-visible-light illumination $\left(0.1-0.3 \mathrm{~mW} / \mathrm{cm}^{2}\right)$, and indoor temperature $\left(25^{\circ} \mathrm{C}\right)$. Photocatalysts with inferior visible-light response and photocarrier transferring cannot actively work under these conditions. More importantly, the ambient durability of photocatalysts should be stressed because of surface fouling/deactivation induced by dust and aerosol particles [28,29]. Herein, a photocatalyst must possess strong visible-light-driven photoactivity, a straightforward reaction pathway, and a self-cleaning surface with long-term stability. With the advantages of narrow bandgap, large specific surface area, and abundant surface $\mathrm{O}_{\mathrm{V}}$-induced active sites, $\mathrm{HAm}-\mathrm{TiO}_{2-\mathrm{x}}$ could be well suited for realistic formaldehyde purification.

In this work, we first reported the preparation of hydrogenated amorphous $\mathrm{TiO}_{2-x}$ nanoparticles and systematically expounded the effects of surface $\mathrm{O}_{\mathrm{V}}$ on its optical bandgap, surface dynamics of photocarriers, and visible-light photoactivity. After functionalized surface hydrogenation by a liquid plasma strategy, the distribution and concentration of $\mathrm{O}_{\mathrm{V}}$ in $\mathrm{HAm}-\mathrm{TiO}_{2-x}$ can be designed well via manipulating the output power of liquid plasma discharge. According to density function theory simulations, one important finding was that the $\mathrm{O}_{\mathrm{V}}$ concentration determined the existence of deep states in the bandgap, while the accurate energy level for these deep states was decided by the $\mathrm{O}_{V}$ distribution. Surface $\mathrm{O}_{V^{-}}$ induced deep states were formed close to the valence band, whereas subsurface $\mathrm{O}_{V}$-induced deep states were mainly generated under the conduction band. With the benefits of narrow bandgap and efficient charge carrier migration, $\mathrm{HAm}-\mathrm{TiO}_{2-x}$ and its coating exhibited excellent visible-light dye degradation and stability. More importantly, low-concentration formaldehyde $(0.6 \mathrm{ppm})$ was completely decomposed in an ambient environment using $\mathrm{HAm}-\mathrm{TiO}_{2-\mathrm{x}}$. The durability test and apparent quantum efficiency of formaldehyde removal under visible light $\left(\lambda=600 \mathrm{~nm}\right.$, power density $\left.=0.136 \mathrm{~mW} / \mathrm{cm}^{2}\right)$ were explored. In 
addition, ROS generation, formaldehyde photodegradation pathway, chemical adsorption energy, and photocatalytic mechanism of $\mathrm{HAm}-\mathrm{TiO}_{2-\mathrm{x}}$ were investigated.

\section{Experimental Section}

\subsection{Reagents and Materials}

Titanium foam (99\%, 100 mesh) and titanium rods (99\%, 3-mm diameter) were acquired from Baoji Hong Xinyuan Metal Material Co., Ltd. (Baoji, China) P25 TiO 2 was purchased from Degussa (Evonik, Essen, Germany).

\subsection{Preparation of $\mathrm{HAm}-\mathrm{TiO}_{2-x}$}

One piece of anodic titanium foam $\left(20 \times 20 \times 2 \mathrm{~mm}^{3}\right)$ and two cathodic titanium rods (3-mm diameter) were placed in an electrical cell that filled with $300-\mathrm{mL}$ nitric acid electrolyte $\left(\mathrm{HNO}_{3}\right)$, as shown in Figure $1 \mathrm{~A}$. Two cathodes were used to generate liquid plasma discharges and to avoid unbalanced flow, as well as to ensure sufficient hydrogenation effects at the double side of the Ti foam. The strong plasma on cathode surfaces was generated by supplying square wave impulse voltages between anodes and cathodes. A water-cooling machine was used to avoid electrolyte evaporation. The surface color of Ti foam varied from pale gray to charcoal gray after $1 \mathrm{~h}$ of liquid plasma treatment. Afterward, the gray titanium foam was put into a beaker filled with $20-\mathrm{mL}$ deionized water and treated with an ultrasonic cleaner for 15 min to obtain a gray liquid, which was then dried with a microwave to obtain gray nanopowders, as shown in Figure 1B. All samples were obtained with the same treatment time $(1 \mathrm{~h})$, output voltage $(700 \mathrm{~V})$, and frequency $(1 \mathrm{kHz})$ but with different output power. The radiation spectra of liquid plasma from 350 to $560 \mathrm{~W}$ were recorded in Figure S1. The resulting sample name was denoted by the output power of the liquid plasma, for example, AT-350 referred to $\mathrm{HAm}_{-} \mathrm{TiO}_{2-\mathrm{x}}$ prepared by applying 350-W output power, AT-420 prepared with $420 \mathrm{~W}$, AT-490 prepared with $490 \mathrm{~W}$, and AT-560 prepared with $560 \mathrm{~W}$.

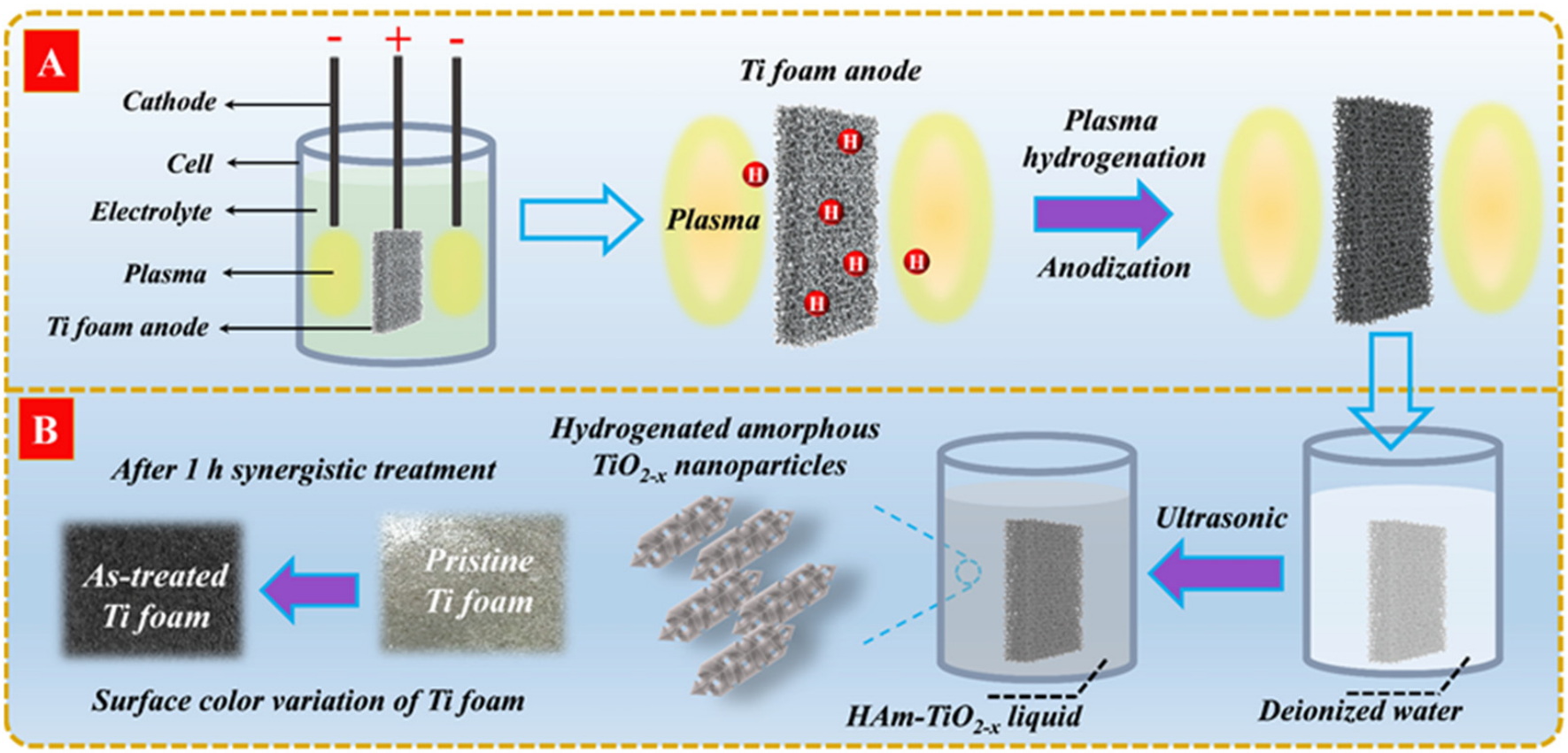

Figure 1. (A) Synthesis setup of producing $\mathrm{HAm}_{-1 \mathrm{TiO}}{ }_{2-x}$, and (B) the generation process of HAm$\mathrm{TiO}_{2-x}$ nanoparticles. 


\subsection{Preparation of $\mathrm{HAm}-\mathrm{TiO}_{2-x}$-Coated Glass}

$\mathrm{HAm}-\mathrm{TiO}_{2-x}$ coated glass was prepared by impregnation method. First, to promote the surface hydrophilicity of the glass substrate, a corona discharger (Zhejiang Ruian Zhilin Corona Equipment Co., Ltd., Ruian, China) was used to make surface superhydrophilicity. Second, the treated glass substrate was put into a well-dispersed $\mathrm{HAm}-\mathrm{TiO}_{2-\mathrm{x}}$ liquid (AT-420, $0.1 \mathrm{mg} / \mathrm{mL}$ ) for $1 \mathrm{~min}$ and was then taken out and dried with a microwave oven to deposit a thin $\mathrm{HAm}_{-} \mathrm{TiO}_{2-x}$ film on the glass.

\subsection{Characterization}

An X-ray powder diffraction instrument (XRD, Rigaku Smartlab, Rigaku, Tokyo,

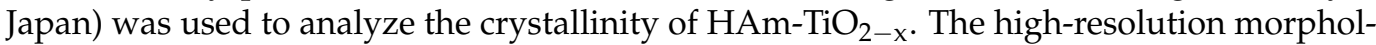
ogy images were acquired by transmission electron microscopy (TEM, JEOL JEM-2100F, JEOL, Tokyo, Japan) with a 200-kV accelerating voltage. A scanning electron microscope (SEM, ZEISS MERLIN, ZEISS, Jena, Germany) was used to characterize the morphology and energy dispersive spectroscopy mapping using $5-\mathrm{kV}$ acceleration voltage. Shimadzu UV-2700 (Shimadzu, Kyoto, Japan) was carried out to measure UV-Vis-diffused reflectance spectroscopy (DRS) at room temperature. A Micromeritics BET analyser (Micromeritics, Norcross, GA, USA) was used to characterize $\mathrm{N}_{2}$ Brunauer, Emmett and Teller (BET) surface area and pore volume of $\mathrm{HAm}-\mathrm{TiO}_{2-x}$. X-ray photoelectron spectrum (XPS, Thermos Escalab 250Xi, Thermo Scientific, Waltham, MA, USA) was used to identify the valence state of surface elements. X-band electron paramagnetic resonance (EPR) was implemented to verify the lattice defects. The surface wetting ability of $\mathrm{HAm}-\mathrm{TiO}_{2-x}$-coated glass was measured using a contact angle meter (KINO SL200KB, KINO Scientific Instrument Inc., Boston, MA, USA). A fluorescence spectrophotometer (F-7100, Hitachi, Tokyo, Japan) was employed to record the photoluminescence spectra (PL) of $\mathrm{HAm}_{-} \mathrm{TiO}_{2-x}$ with $365-\mathrm{nm}$ excitation wavelength. Electrochemical workstation (CHI660E, CH Instruments, Inc., Austin, TX, USA) was applied for measurement of photocurrent density. A Thermo Scientific DXR Raman microscope equipped with a 532-nm laser excitation was used to record Raman spectra at room temperature. X-band EPR spectra for active species trapping experiments were applied by using a Bruker EMX PLUS (Bruker, Billerica, MA, USA). In-situ diffused Fourier transform infrared spectroscopy (In-situ DRIFTS, PerkinElmer Spotlight 400, Waltham, MA, USA) was applied during formaldehyde photodegradation. The emitted spectra of liquid plasma discharge were recorded by a spectrometer (Ocean Optics Maya 2000 pro, Ocean Insight, Orlando, FL, USA).

The positron annihilation lifetime spectrum owns a ${ }^{22} \mathrm{Na}$ positron emission source and its activity is approximately $2 \times 10^{6} \mathrm{~Bq}$. The positrons with a kinetic energy of $0-540 \mathrm{keV}$ are produced when the source undergoes $\beta^{+}$decay and, almost simultaneously, emits $\gamma$ photons $(1.28 \mathrm{MeV})$. Therefore, the appearance of this gamma photon can be regarded as the starting time for generating positrons; the appearance of $0.511 \mathrm{MeV}$ annihilation gamma photons is the end of the positron annihilation event; this interval is the positron lifetime. The radioactive source is sandwiched between the sample to form a sandwich structure with a total of 2 million counts and, herein, the positron annihilation lifetime spectrum is already recorded. The time resolution of the system is approximately $190 \mathrm{ps,}$ with a track width of 12.5 ps.

\subsection{Photodegradation Experiments of $\mathrm{HA}-\mathrm{TiO}_{2-x}$}

2.5.1. The Dyes Photodegradation of $\mathrm{HAm}_{-} \mathrm{TiO}_{2-\mathrm{x}}$ Nanoparticles and Their Coatings

The photoactivity of $\mathrm{HAm}_{-} \mathrm{TiO}_{2-\mathrm{x}}$ was assessed by photodegradation of rhodamine $\mathrm{B}$ $(\mathrm{RhB})$ under visible light $(420-800 \mathrm{~nm})$. First, $\mathrm{HAm}^{-\mathrm{TiO}_{2-\mathrm{x}}}$ nano-powders $(50 \mathrm{mg})$ and RhB solution $(20 \mathrm{mg} / \mathrm{L}, 50 \mathrm{~mL})$ were put into a beaker with 60-min magnetic stirring for adsorption-desorption equilibrium. During photodegradation, 1-mL of solution was taken out from the beaker to test its absorbance at 554-nm wavelength via spectrophotometer. To evaluate the stability of $\mathrm{HAm}-\mathrm{TiO}_{2-x}, \mathrm{AT}-420$ was preserved in water for 7 days for the subsequent use under the same experimental conditions. Furthermore, $\mathrm{HAm}_{-} \mathrm{TiO}_{2-\mathrm{x}}$ coat- 
ing was applied to decompose RhB and methyl blue (MB). For the RhB photodegradation experiment, a $2-\mathrm{mL} \mathrm{RhB}$ solution $(20 \mathrm{mg} / \mathrm{L})$ was dropped on the $\mathrm{HAm}^{-\mathrm{TiO}_{2-x}}$ coating $\left(10 \times 5 \times 0.3 \mathrm{~cm}^{3}\right)$, which was then dried in an oven for $10 \mathrm{~min}$; afterward, the treated $\mathrm{HAm}-\mathrm{TiO}_{2-\mathrm{x}}$ coating was irradiated with visible light for $1 \mathrm{~h}$. During the decomposition of $\mathrm{MB}, \mathrm{HAm}-\mathrm{TiO}_{2-\mathrm{x}}$ coating $\left(2 \times 2 \times 0.3 \mathrm{~cm}^{3}\right)$ was immersed in a $10-\mathrm{mL} \mathrm{MB}$ solution $(20 \mathrm{mg} / \mathrm{L})$ to test its visible-light photoactivity.

The in-situ trap of spin-reactive species under visible-light illumination was recorded by the EPR signals of $\cdot \mathrm{O}_{2}{ }^{-}$and $\cdot \mathrm{OH}$ using 5,5-dimethyl-1-pyrroline-N-oxide (DMPO). In addition, in reactive species trapping experiments, the concentration of all sacrifice agents was $0.2 \mathrm{mM} / \mathrm{mL}$, including ammonium oxalate (AO), Fe (II)-EDTA, potassium iodide (KI), p-benzoquinone (BQ), and isopropanol (IPA).

\subsubsection{Formaldehyde (HCHO) Photodecomposition Test over $\mathrm{HAm}-\mathrm{TiO}_{2-x}$}

Photocatalytic elimination of $\mathrm{HCHO}$ was performed in a sealed box $\left(1 \times 1 \times 1 \mathrm{~m}^{3}\right)$ at room temperature $\left(25^{\circ} \mathrm{C}\right.$, relative humidity $\left.=52 \%\right)$ under visible-light irradiation. The xenon lamp was placed inside the box as the visible-light source, which was equipped with a bandpass filter glass centered at $600 \mathrm{~nm}$ (full width at half maximum $(\mathrm{FWHM})=15 \mathrm{~nm}$ ). The $\mathrm{HAm}-\mathrm{TiO}_{2-x}$ coating was deposited on a stainless-steel plate $\left(3036 \mathrm{~cm}^{2}\right)$ with a loading of $1 \mathrm{mg} / \mathrm{cm}^{2}$; afterward, this stainless-steel plate was placed below the xenon lamp. The power density of irradiated light on the stainless-steel plate was $0.136 \mathrm{~mW} / \mathrm{cm}^{2}$. A certain amount of 38\% $\mathrm{HCHO}$ was injected into the sealed box; a 7-W fan was used to ensure proper $\mathrm{HCHO}$ diffusion. After dark adsorption-desorption equilibrium, the preliminary concentration of $\mathrm{HCHO}$ was approximately $0.6 \mathrm{ppm}$. During photodegradation, an $\mathrm{HCHO}$ tester (PPM-HTV, UK) was used to record the real-time HCHO concentrations. The HCHO photocatalytic formaldehyde mineralization efficiency $(\eta)$ was measured by the equation: $\eta(\%)=\left(C_{0}-C_{t}\right) / C_{0} \times 100 \%$, where $C_{0}$ and $C_{t}$ describe instant HCHO concentrations at 0 and $t h$, respectively. In addition, 365-nm UV light-mediated HCHO photodegradation was performed under the same conditions except for the light source.

Apparent quantum efficiency (AQY) of HCHO photodegradation was defined as Equations (1)-(3) [30]:

$$
\begin{gathered}
\mathrm{AQY}=\frac{\text { number of degraded pollutant molecules }}{\text { number of photons entering the reactor }} \times 100 \% \\
\mathrm{~N}_{\mathrm{M}}=\mathrm{N}_{\mathrm{A}} \times \mathrm{n}_{\mathrm{HCHO}}=\mathrm{N}_{\mathrm{A}} \times\left(\left(\mathrm{C}_{0}-\mathrm{C}_{\mathrm{t}}\right) \times \mathrm{V}\right) /(30 \times 1000) \\
\text { number of photons entering the reactor }=\mathrm{I} \times \mathrm{S} /(\mathrm{hc} / \lambda) \times \mathrm{t}
\end{gathered}
$$

where $\mathrm{N}_{\mathrm{M}}, \mathrm{N}_{\mathrm{A}}, \mathrm{n}_{\mathrm{HCHO}}, \mathrm{C}_{0}, \mathrm{C}_{\mathrm{t}}$, and $\mathrm{V}$ represent the number of degraded pollutant molecules, Avogadro's constant, moles of degraded $\mathrm{HCHO}$, initial $\mathrm{HCHO}$ concentration, $\mathrm{HCHO}$ concentration of $t h$, and volume of the box, respectively. While $\mathrm{I}, \mathrm{S}, \mathrm{h}, \mathrm{c}, \lambda$, and $\mathrm{t}$ are illumination intensity, area, Planck's constant, the vacuum speed of light, the incident light wavelength, and illumination time, respectively.

\subsection{Theoretical Calculation Methods}

To complete all spin-polarization density functional theory (DFT) calculations, with the Perdew-Burke-Ernzerhof (PBE) formulation, the first-principles were employed within the generalized gradient approximation (GGA) [31-33]. The projected augmented wave (PAW) potentials were selected to illustrate the ionic cores and took valence electrons into account $[34,35]$. Through the Gaussian smearing method, partial occupancies of the KohnSham orbitals were used with $0.05-\mathrm{eV}$ width. When the energy change was lower than $10^{-4} \mathrm{eV}$, the electronic energy was regarded as self-consistent. When the energy change was lower than $0.05 \mathrm{eV} \AA^{-1}$, a geometry optimization was identified as convergent; the vacuum spacing from the structural plane was $18 \AA$. The $\mathrm{TiO}_{2}(101)$ amorphous structure was obtained by ab initio first-principles molecular dynamics (AIMD) simulation calculation with 20 ps using the $300 \mathrm{~K}$. In addition, the $\mathrm{TiO}_{2}(101)$ crystal structure had been optimized 
using the AIMD simulations with the 1-fs step and $300 \mathrm{~K}$; this crystal structure was then changed into amorphous $\mathrm{TiO}_{2}$ (101). Finally, it was relaxed using DFT calculations in order to obtain the $\mathrm{TiO}_{2}(101)$ stable amorphous structure.

\section{Results and Discussion}

\subsection{Characterization of $\mathrm{HAm}-\mathrm{TiO}_{2-x}$}

Figure $2 \mathrm{~A}$ exhibits the XRD patterns for all $\mathrm{HAm}-\mathrm{TiO}_{2-\mathrm{x}}$. Here, we provided two XRD cards of crystalline $\mathrm{TiO}_{2}$-involved anatase (PDF\#21-1272) and rutile (PDF\#21-1276). No apparent peaks indexed to crystalline phase are detected, but the weak and broad peaks at (101) facet of all samples compared with that of $\mathrm{P} 25 \mathrm{TiO}_{2}$ indicates that a long-term disordered defect was generated. Figure S2 displays the surface atomic bond environment of all samples by Raman spectra. The observed broad and blue shift of $E_{g}$ mode in our case could be ascribed to the surface oxygen vacancies in $\mathrm{HAm}_{-} \mathrm{TiO}_{2-x}$ [36]. Figure $2 \mathrm{~B}$ shows the light response performance of all $\mathrm{HAm}-\mathrm{TiO}_{2-\mathrm{x}}$ using DRS spectra. All samples display enhanced visible light absorption; the bandgaps of AT-350, AT-420, AT-490, and AT-560 are estimated to be $2.74,2.36,2.57$, and $2.91 \mathrm{eV}$, respectively. The plots of $(\alpha \mathrm{hv})^{1 / 2}$ versus $\mathrm{h} v$ by using the Kubelka-Munk function were seen in Figure S3. Given the above results, some self-doped defects should exist in $\mathrm{HAm}_{-} \mathrm{TiO}_{2-\mathrm{x}}$. To verify the existence of the surface defect on $\mathrm{HAm}-\mathrm{TiO}_{2-x}$, EPR spectrum was implemented, as seen in Figure 2C. A sharp EPR signal of $g=2.004$ is evidence that the AT-420 sample possessed oxygen vacancies [37]. In addition, Figure 2D illustrates the size and structure of the nanopore using nitrogen adsorption-desorption isotherms. The pore structure in $\mathrm{HAm}^{-\mathrm{TiO}_{2-x}}$ was irregular, which was proven by the as-obtained typical IV curves with hysteresis loops. It was indicated that micropores and/or mesoporous were formed, owing to the hysteresis with the $\mathrm{P} / \mathrm{P}_{0}$ range of $0.7-0.9$; the pore size was nearly $3.4 \mathrm{~nm}$, as displayed in the inset. The large BET $\left(176.7 \mathrm{~cm}^{2} \mathrm{~g}^{-1}\right)$ and pore volume $\left(0.33 \mathrm{~cm}^{3} \mathrm{~g}^{-1}\right)$ in $\mathrm{Ham}-\mathrm{TiO}_{2-\mathrm{x}}$ both contribute to the large capturing of polluted molecules.
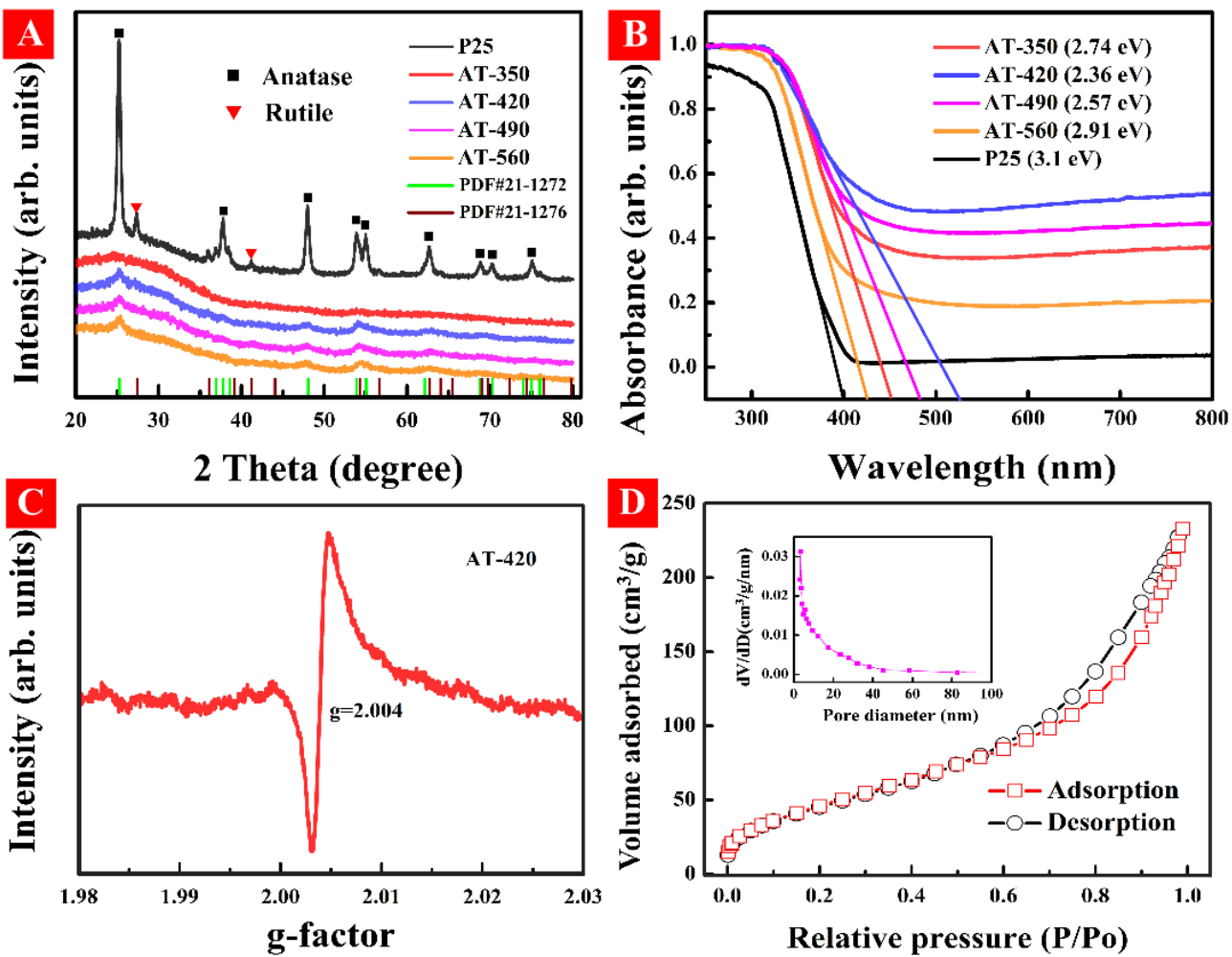

Figure 2. (A) The X-ray diffraction (XRD) patterns and (B) UV-vis diffuse-reflectance spectra for all as-prepared samples. (C) EPR spectrum and (D) nitrogen adsorption-desorption isotherms of AT-420 sample, inset is the pore diameter distribution calculated by the BJH method. 
To investigate the morphology characterizations in $\mathrm{Ham}-\mathrm{TiO}_{2-\mathrm{x}}, \mathrm{TEM}$ was conducted, as displayed in Figure 3. As shown in Figure 3A, $\mathrm{HAm}-\mathrm{TiO}_{2-x}$ nanoparticles display irregular strip structure. As shown in Figure 3B, lots of textures marked with yellow rectangles exist in the nanoparticles, which seem similar to the leaf vein; these vein-like morphology features are deemed to be the irregular mesoporous structure. As shown in Figure 3C, a curve-liked bulk defect marked with yellow oval was as roughly $20 \mathrm{~nm}$ long; furthermore, the disordered surface marked with yellow rectangle proves that surface amorphization with 1-2 nm thickness is prepared after liquid plasma treatment. No longterm range crystalline structure was observed, but some crystal lattices $(d=0.353 \mathrm{~nm})$ of anatase (101) facet existed in $\mathrm{HAm}_{-} \mathrm{TiO}_{2-\mathrm{x}}$, which was in good accordance with the XRD results in Figure 2A. Figure 3D exhibits several nanopores marked with yellow circles with lengths of 2-3 nm, which is classified into mesopore and in good consistency with Barrett-Joyner-Halenda $(\mathrm{BJH})$ result. Overall, $\mathrm{HAm}-\mathrm{TiO}_{2-x}$ not only possesses the typical characteristics of amorphous materials, including long-term disorder lattice and large specific surface area, but also has broad visible-light harvest and disordered surface on the amorphous core.
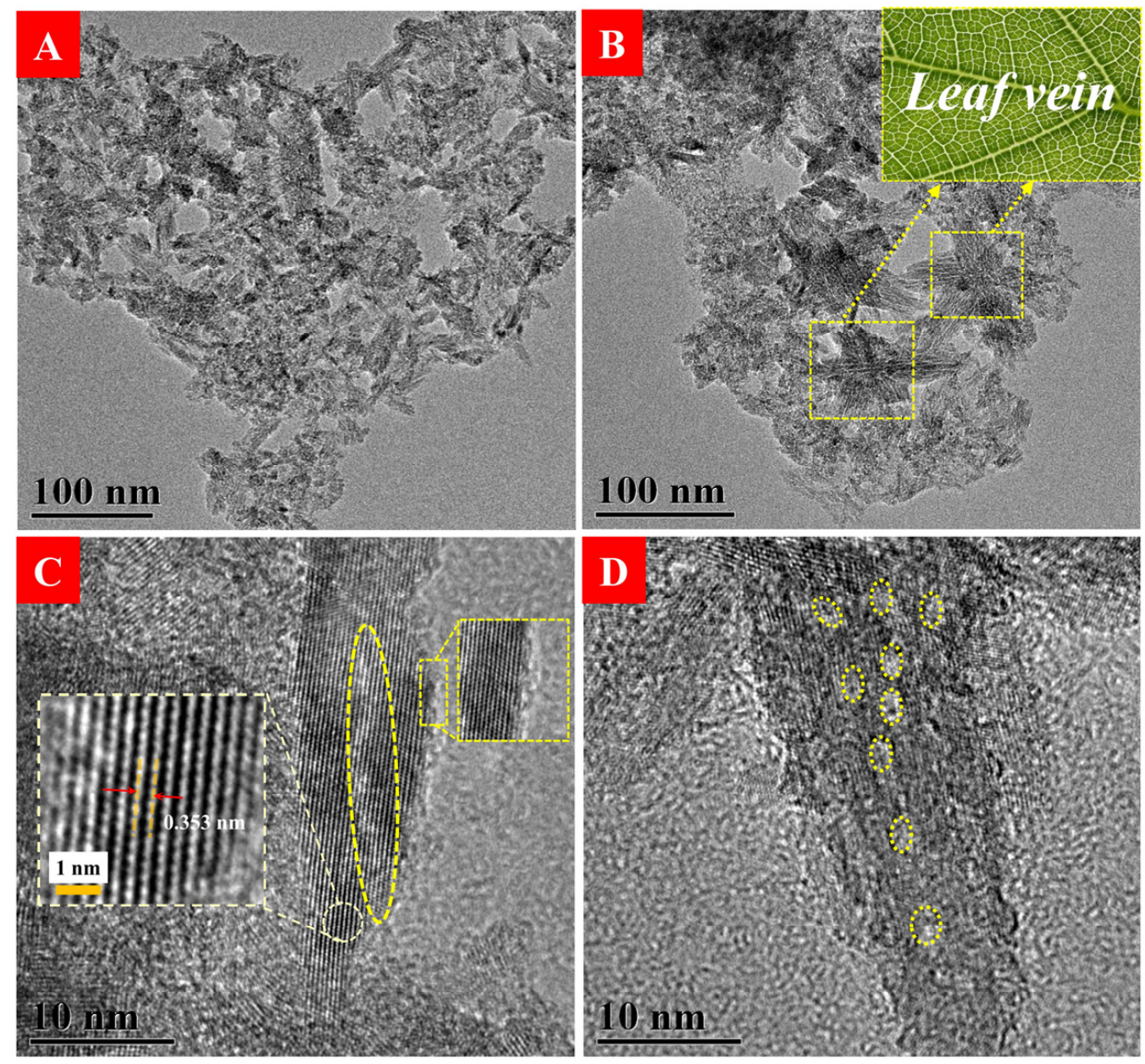

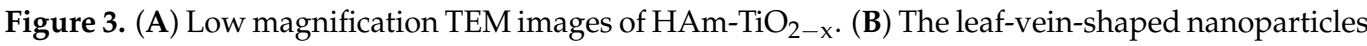
in $\mathrm{HAm}-\mathrm{TiO}_{2-\mathrm{x}}$, the inset was a photograph of the leaf vein. (C) The curve-like bulk defect marked with yellow oval and the disordered surface marked with yellow rectangle; the crystal plane spacing (d-spacing) was calculated to be $0.353 \mathrm{~nm}$ as shown in the left dotted box. (D) Some mesoporous structures marked with yellow circles in $\mathrm{HAm}_{-} \mathrm{TiO}_{2-\mathrm{x}}$. 


\subsection{Regulation of Surface $\mathrm{O}_{V}$ and Bandgap Engineering in $\mathrm{HAm}-\mathrm{TiO}_{2-x}$}

Positron annihilation spectrometry (PAS) is a powerful tool that can be used to characterize the size, type, concentration, and distribution of surface defects in nanomaterials. As listed in Table 1, the relative intensities of three positron lifetime components denoted as $\tau_{1}, \tau_{2}$, and $\tau_{3}$ are $I_{1}, I_{2}$, and $I_{3}$, respectively. The largest component $\left(\tau_{3}\right)$ is generally regarded as the signal of large voids [38]. The second-largest lifetime component $\left(\tau_{2}\right)$ can be attributed to larger size defects, for instance, $\mathrm{O}_{\mathrm{V}}$ clusters or surface defects [39]. The smallest component $\left(\tau_{1}\right)$ is responsible for free positrons annihilation with the lattice and at small $\mathrm{O}_{\mathrm{V}}$ sites on the subsurface [40]. When the output power increased (AT-350 to AT-420), $\mathrm{I}_{1}$ decreased, while $\mathrm{I}_{2}$ increased, and, notably, $\mathrm{I}_{3}$ of AT- 420 was too small to detect. This observation indicates that the lattice $\mathrm{O}_{V}$ moved to the surface to form surface $\mathrm{O}_{V}$, which was then accumulated on the catalyst surface and, thus, shielded the LV signal. With a further increase in output power (from AT-420 to AT-560), $\mathrm{I}_{1}$ increased but $\mathrm{I}_{2}$ decreased; both the intensities of $\mathrm{I}_{3}$ for AT- 420 and AT- 490 were not detected, whereas $\mathrm{I}_{3}$ of AT-560 emerged. It was, therefore, concluded that surface $\mathrm{O}_{\mathrm{V}}$ moved back to the inner lattice to form subsurface $\mathrm{O}_{\mathrm{V}}$ in sample AT-560. In conclusion, these results confirm that the outputpower-regulated $\mathrm{O}_{\mathrm{V}}$ not only distributed on the surface but also on the subsurface, rather than merely accumulating on the catalyst surface. More importantly, $\mathrm{O}_{\mathrm{V}}$ in $\mathrm{HAm}-\mathrm{TiO}_{2-\mathrm{x}}$ existed preferentially at the subsurface if it underwent strong liquid plasma treatment. Compared with the surface $\mathrm{O}_{\mathrm{V}}$, subsurface and inner-bulk $\mathrm{O}_{\mathrm{V}}$ are considered quite stable, as the outermost amorphous layer can prevent gradual oxidation by air and water [19,41].

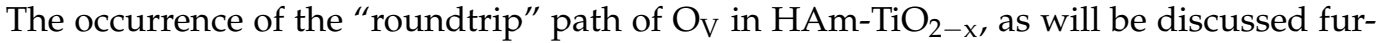
ther in what follows, could be a result of the synergistic effect of liquid plasma-induced hydrogenation and anodization.

Table 1. Positron lifetime and relative intensities of $\mathrm{HAm}^{-\mathrm{TiO}_{2-\mathrm{x}}}$, where the $\mathrm{O}_{\mathrm{VL}}, \mathrm{O}_{\mathrm{VS}}$, and $\mathrm{LV}$ are attributed to lattice $\mathrm{O}_{\mathrm{V}}$, surface $\mathrm{O}_{\mathrm{V}}$, and large voids, respectively.

\begin{tabular}{|c|c|c|c|c|c|c|}
\hline Sample & $\tau_{1}(\mathrm{~ns})$ & $\mathrm{O}_{\mathrm{VL}}-\mathrm{I}_{1}-\%$ & $\tau_{2}$ (ns) & $\mathrm{O}_{\mathrm{VS}}-\mathrm{I}_{2}-\%$ & $\tau_{3}(\mathrm{~ns})$ & LV-I $I_{3}-\%$ \\
\hline AT-350 & 0.323 & 77.1 & 0.453 & 22.6 & 5.142 & 0.3 \\
\hline AT- 420 & 0.224 & 10.8 & 0.363 & 89.2 & / & / \\
\hline AT- 490 & 0.247 & 15.4 & 0.369 & 84.6 & / & 1 \\
\hline AT-560 & 0.329 & 87.8 & 0.526 & 11.8 & 3.797 & 0.4 \\
\hline
\end{tabular}

To inspect the surface chemical states, XPS spectra were performed in $\mathrm{HAm}-\mathrm{TiO}_{2-\mathrm{x}}$. As seen in full XPS spectra of Figure 4A, the lack of obvious differences between these samples demonstrated that the element components were identical. As shown in Figure 4B, $\mathrm{P} 25 \mathrm{TiO}_{2}$ had two typical binding energies of Ti $2 \mathrm{p}_{3 / 2}(459.2 \mathrm{eV})$ and Ti $2 \mathrm{p}_{1 / 2}(465.2 \mathrm{eV})$ attributed to $\mathrm{Ti}^{4+}$ peaks $[42,43]$. In comparison, an apparent shift toward lower binding energies was observed for the sample AT-420, which suggested that $\mathrm{Ti}^{3+}$ existed on the disordered surface. We, thus, subtracted the Ti $2 p$ spectra of $\mathrm{P}_{2} 5 \mathrm{TiO}_{2}$ from that of sample AT-420, as seen in the bottom of Figure 4B; the resultant orange spectrum curve received two evident peaks (458.2 and $463.7 \mathrm{eV}$ ) ascribed to the $\mathrm{Ti}^{3+}\left(\mathrm{Ti}_{2} \mathrm{p}_{3 / 2}\right.$ and $\mathrm{Ti} 2 \mathrm{p}_{1 / 2}$ ) [44,45]. To calculate the ratio of $\mathrm{Ti}^{3+} / \mathrm{Ti}^{4+}$, the deconvoluted spectra of Ti $2 \mathrm{p}$ are provided in Figure $4 \mathrm{C}$; the ratio was calculated by the areas of $\mathrm{Ti}^{3+}$ and $\mathrm{Ti}^{4+}$ at $\mathrm{Ti} 2 \mathrm{p}_{3 / 2}$ [46]. The highest $\mathrm{Ti}^{3+} / \mathrm{Ti}^{4+}$ ratio in AT-420 confirmed the highest concentration of $\mathrm{Ti}^{3+}$ in these samples, which is consistent with the PAS results; the detailed data regarding the $\mathrm{Ti}^{3+} / \mathrm{Ti}^{4+}$ ratio are displayed in Table 2. As shown in Figure 4D, three kinds of high-resolution $\mathrm{O}$ 1s peaks were observed, which were considered as the lattice oxygen (lattice $\mathrm{O}, 530.1 \mathrm{eV}$ ), surface oxygen defects (O deficiency, $531.9 \mathrm{eV}$ ), and hydroxyl group oxygen (hydroxyl $\mathrm{O}, 533.1 \mathrm{eV}$ ) [47,48]. As comparison, a much stronger peak intensity of O deficiency in AT-420 demonstrated a higher content of surface $\mathrm{O}_{\mathrm{V}}$. Furthermore, the clear shift toward lower binding energy for the lattice O peak observed in sample AT- 420 was due to the high-density surface oxygen vacancies [49]. Therefore, as shown in Figure 4B-D, compared with $\mathrm{P}_{25} \mathrm{TiO}_{2}$, an 
apparent blue shift $(0.1 \mathrm{eV})$ in Ti $2 \mathrm{p}$ and $\mathrm{O} 1$ s spectra were observed, which confirmed the existence of surface defects of $\mathrm{Ti}^{3+}$ and $\mathrm{O}_{\mathrm{V}}$ on the disordered surface. To clarify the effect of $\mathrm{Ti}^{3+}$ concentration on bandgap structure modification, the XPS valence band maximum (VBM) spectra of $\mathrm{HAm}-\mathrm{TiO}_{2-\mathrm{x}}$ were investigated, as shown in Figure S4. The estimated VBM value for all samples was recorded in Table 2. Herein, according to Table 2, the band structures for all samples are displayed in Figure 5. It is clear that sample AT-420 exhibited the highest position of the valence band, which could induce a strong redox reaction and higher photoactivity. Notably, the electric potential of $\mathrm{h}^{+}$was higher than all samples, indicating that it is possible to disable UV-light-induced photoactivity in $\mathrm{HAm}^{-\mathrm{TiO}_{2-x}}$. Here, the output-power-controlled bandgap engineering in $\mathrm{HAm}^{-\mathrm{TiO}_{2-x}}$ was realized, which was obtained via the regulation of the distribution and the concentration of $\mathrm{O}_{\mathrm{V}}$.
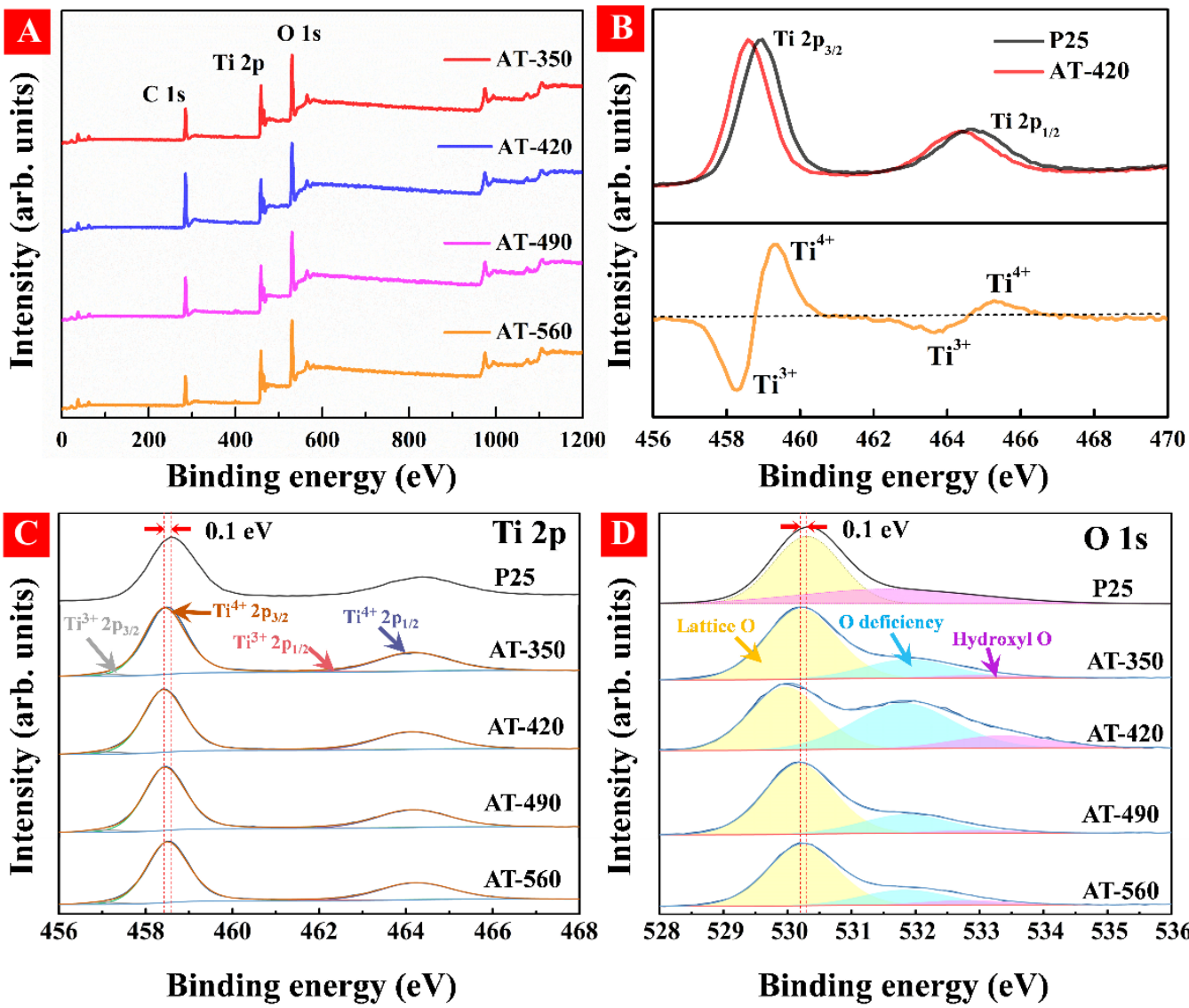

Figure 4. (A) Full XPS spectra for all samples, (B) Ti $2 \mathrm{p}$ spectra of AT-420 and P25 $\mathrm{TiO}_{2}$. The deconvoluted Ti 2p (C) and O 1s (D) spectra for all samples.

Table 2. Bandgap, valence band maximum, and $\mathrm{Ti}^{3+} / \mathrm{Ti}^{4+}$ ratio of the $\mathrm{HAm}-\mathrm{TiO}_{2-x}$ samples.

\begin{tabular}{ccccc}
\hline Sample & AT-350 & AT-420 & AT-490 & AT-560 \\
\hline Output power $(\mathrm{W})$ & 350 & 420 & 490 & 560 \\
Bandgap $(\mathrm{eV})$ & 2.74 & 2.36 & 2.57 & 2.91 \\
VBM $(\mathrm{eV})$ & 2.48 & 2.16 & 2.33 & 2.58 \\
${\text { Ratio of } \mathrm{Ti}^{3+} / \mathrm{Ti}^{4+}}^{2.81 \%}$ & $3.01 \%$ & $2.91 \%$ & $2.69 \%$ \\
\hline
\end{tabular}




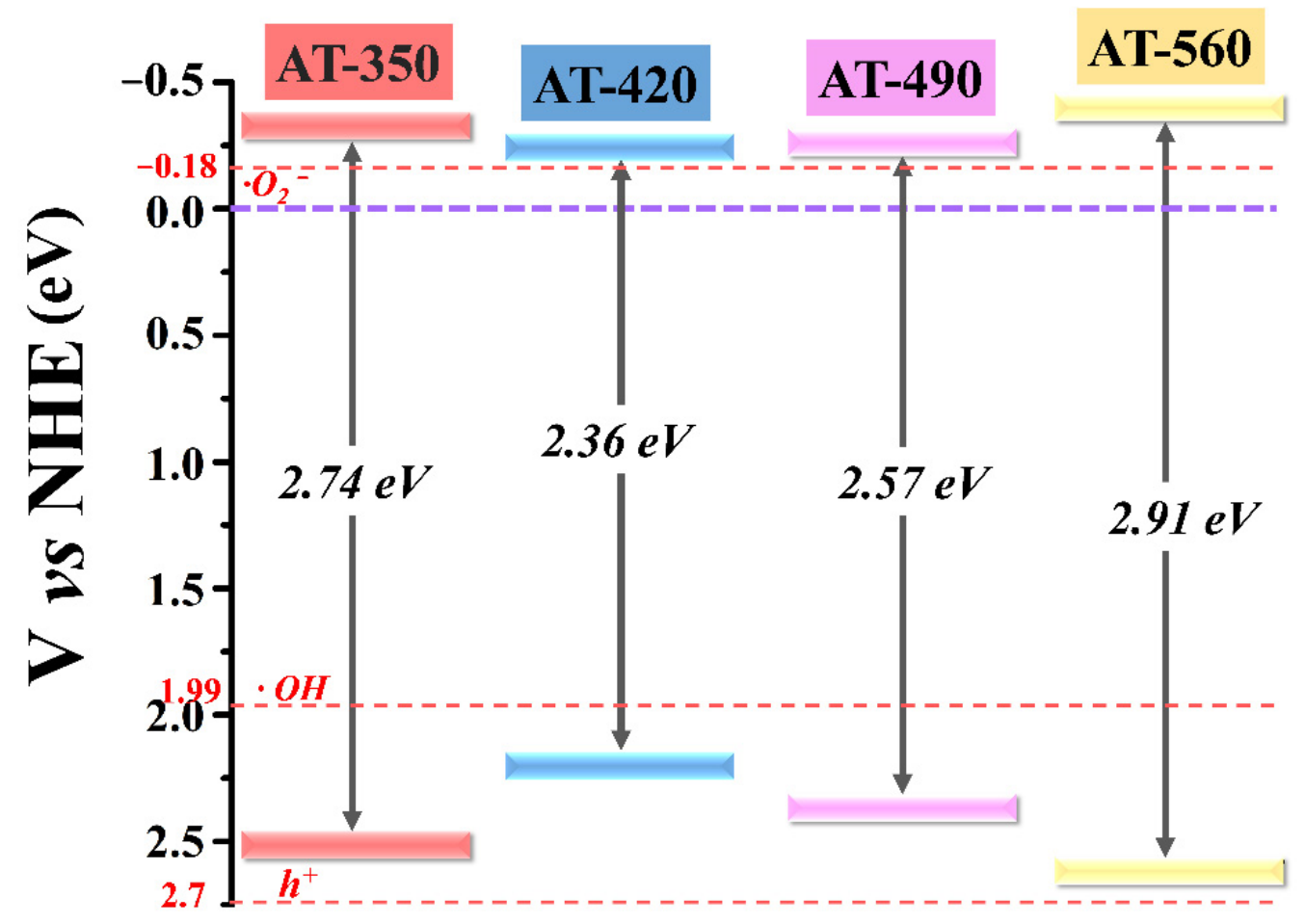

Figure 5. The bandgap structures of all samples.

\subsection{Effect of Distribution and Concentration of $O_{V}$ on Electrical Structure}

The above PAS and XPS results indicated that the bandgap engineering of HAm$\mathrm{TiO}_{2-x}$ could be directly achieved via the regulation of the distribution and concentration of $\mathrm{O}_{\mathrm{V}}$. However, an in-depth understanding of the effect of distribution and concentration of $\mathrm{O}_{\mathrm{V}}$ on the regulation mechanism of the refined bandgap structure was still missing. Thus, DFT calculations regarding the effect of distribution and concentration of $\mathrm{O}_{\mathrm{V}}$ on the electrical structures of $\mathrm{HAm}-\mathrm{TiO}_{2-x}$ were carried out here. To balance the distribution and concentration of $\mathrm{O}_{\mathrm{V}}$, we used five kinds of atomic models, denoted as: Surface- $1 \mathrm{O}_{\mathrm{V}}$, Surface $-4 \mathrm{O}_{V}$, Surface $-2 \mathrm{O}_{v}$ and Subsurface $-2 \mathrm{O}_{V}$, Subsurface $-1 \mathrm{O}_{V}$, and Subsurface $-4 \mathrm{O}_{V}$, as depicted in Figure 6a-e, respectively. The naming system used here is such that the model of Surface- $1 \mathrm{O}_{\mathrm{V}}$ represented the case in which one oxygen vacancy is located on the surface, and the model of Surface- $2 \mathrm{O}_{\mathrm{V}}$ and Subsurface- $-2 \mathrm{O}_{\mathrm{V}}$ denoted two oxygen vacancies on the surface and two oxygen vacancies at the subsurface. The electronic band structures and density of states (DOS) of all models are displayed in Figure $6 \mathrm{f}-\mathrm{j}$. With the increase in the amount of surface $\mathrm{O}_{\mathrm{V}}\left(\right.$ Surface- $1 \mathrm{O}_{\mathrm{V}}$ to Surface- $\left.4 \mathrm{O}_{\mathrm{V}}\right)$, deep trap states were generated above the valence band $(\sim 0.6 \mathrm{eV})$, and the flat deep states indicated large effective mass and restricted charge mobility, which led to photocarrier recombination. Owing to the introduction of deep states, some potential transitions may occur, including valence band to $\mathrm{O}_{\mathrm{V}}$-induced deep states (VB-O $\mathrm{O}_{\mathrm{VS}}$ ), valence band to conduction band (VB-CB), and $\mathrm{O}_{\mathrm{V}}$ induced deep states to the conduction band $\left(\mathrm{O}_{\mathrm{VS}}-\mathrm{CB}\right)$, as depicted in Figure $6 \mathrm{~g}$. When the surface $\mathrm{O}_{V}$ moved to the inner domain to form subsurface $\mathrm{O}_{\mathrm{V}}\left(\right.$ Surface- $4 \mathrm{O}_{\mathrm{V}}$ to Surface- $-2 \mathrm{O}_{V}$ and Subsurface- $\left.2 \mathrm{O}_{\mathrm{V}}\right)$, deep trap states upshifted near the conduction band $(\sim 0.5 \mathrm{eV})$. In comparison with $\mathrm{O}_{\mathrm{VS}}-\mathrm{CB}$ transition in the Surface- $4 \mathrm{O}_{\mathrm{V}}$ model, the transition observed in Surface $-2 \mathrm{O}_{V}$ and Subsurface- $2 \mathrm{O}_{V}$ was of much lower energy, which could induce a longer wavelength photoresponse, as shown in Figure $6 \mathrm{~h}$. When surface $\mathrm{O}_{\mathrm{V}}$ moved entirely into the inner region (Subsurface-1 $\mathrm{O}_{\mathrm{V}}$ ), as depicted in Figure 6d, deep trap states disappeared, but several conduction band tails emerged, as shown in Figure 6i, which resulted in a much narrower bandgap. By further increasing subsurface $\mathrm{O}_{V}\left(\right.$ Subsurface- $\left.4 \mathrm{O}_{V}\right)$, as seen in Figure $6 \mathrm{j}$, deep trap states close to the conduction band $(\sim 0.5 \mathrm{eV})$ reemerged. In summary, the $\mathrm{O}_{\mathrm{V}}$ concentration determined the existence of deep trap states in the bandgap, and the $\mathrm{O}_{\mathrm{V}}$ distribution determined their exact location. High concentration of surface $\mathrm{O}_{\mathrm{V}}$ could 
introduce the deep trap states, while $\mathrm{O}_{V}$ at the subsurface could upshift the deep trap states. On the basis of the PAS results, subsurface $\mathrm{O}_{\mathrm{V}}$ was a substantial support in $\mathrm{HAm}-\mathrm{TiO}_{2-\mathrm{x}}$ which suggests that the refined electrical structure of $\mathrm{HAm}_{-} \mathrm{TiO}_{2-x}$ could follow the model of Subsurface- $4 \mathrm{O}_{\mathrm{V}}$, generating deep trap states near the conduction band.

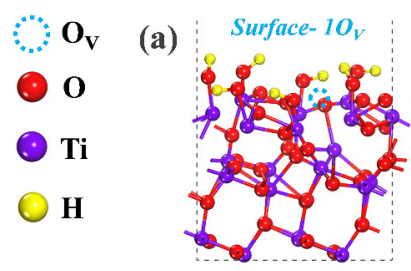

(b)
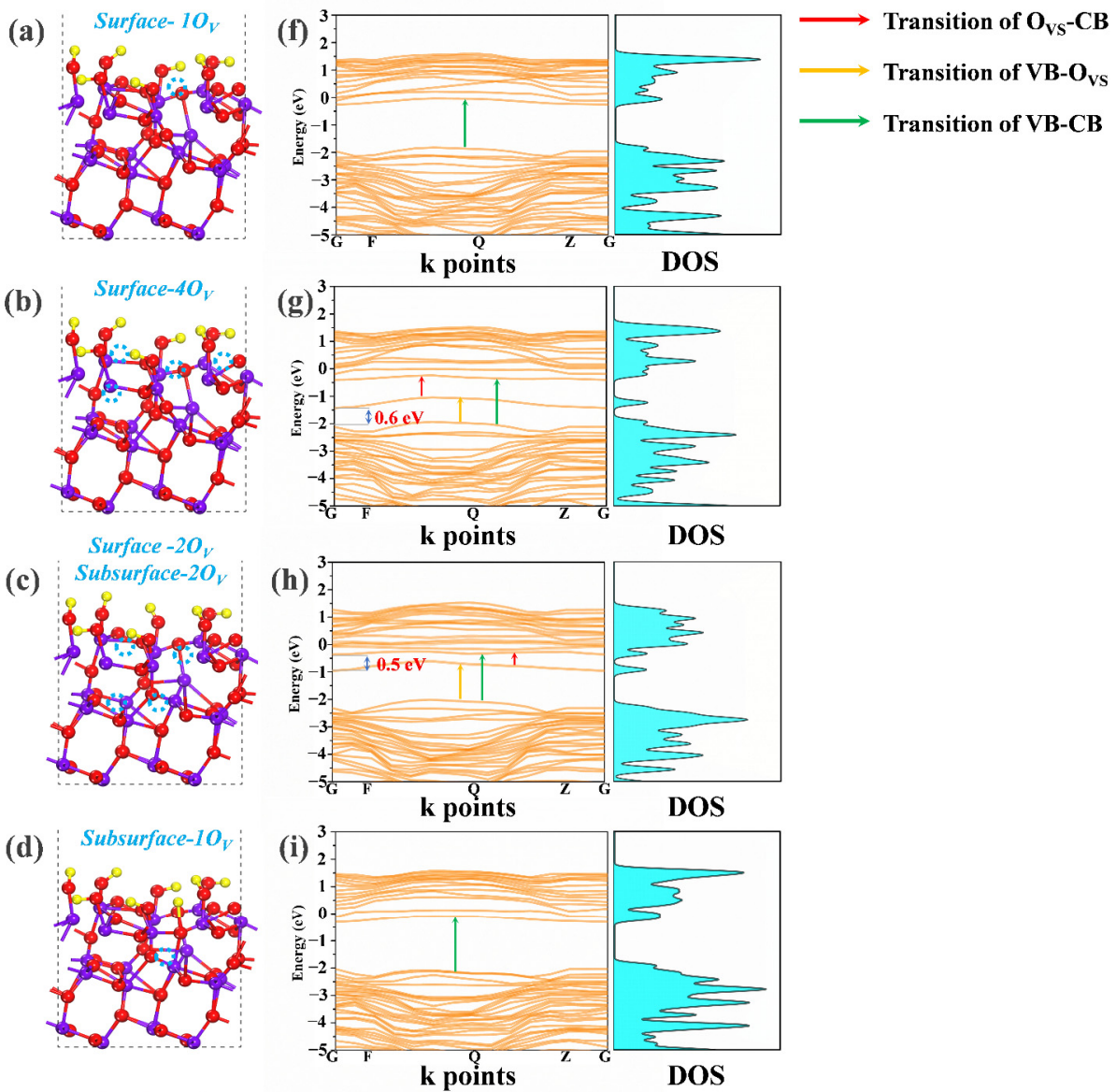

(e)
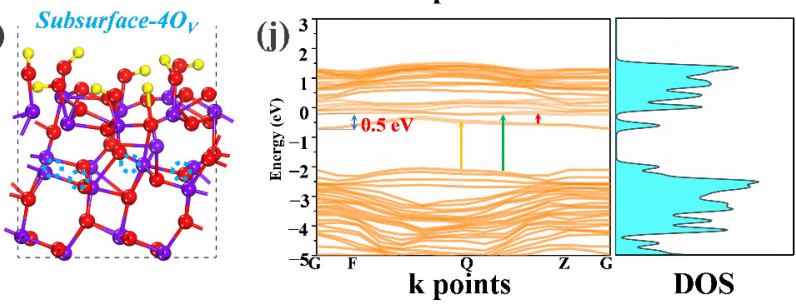

Figure 6. Five kinds of atomic models are shown in (a-e), respectively, and the corresponding band structure and DOS are shown in $(\mathbf{f}-\mathbf{j})$.

\subsection{The Photo-Generated Carrier Activity of $\mathrm{HAm}_{-} \mathrm{TiO}_{2-x}$}

To explore the influence of subsurface $\mathrm{O}_{\mathrm{V}}$ on the production and transferability of photogenerated charge carriers, the transient photocurrent density and PL spectra were explored using visible-light irradiation. As shown in Figure 7A, AT-420 displayed the highest photocurrent density among these samples, revealing the largest photoinduced carrier production and more efficient charge carrier separation. As displayed in Figure 7B, the PL spectra were measured to evaluate the photo-generated $\mathrm{e}-\mathrm{h}$ pairs separation and transfer efficiency. It is clear that sample AT-420 exhibited the lowest intensity of all the samples, suggesting accelerated photoinduced carrier separation and transfer. Therefore, subsurface $\mathrm{O}_{\mathrm{V}}$ in $\mathrm{HAm}_{-} \mathrm{TiO}_{2-\mathrm{x}}$ contributed to the generation and transferring ability of photocarriers, which could greatly increase its visible-light photoactivity. 

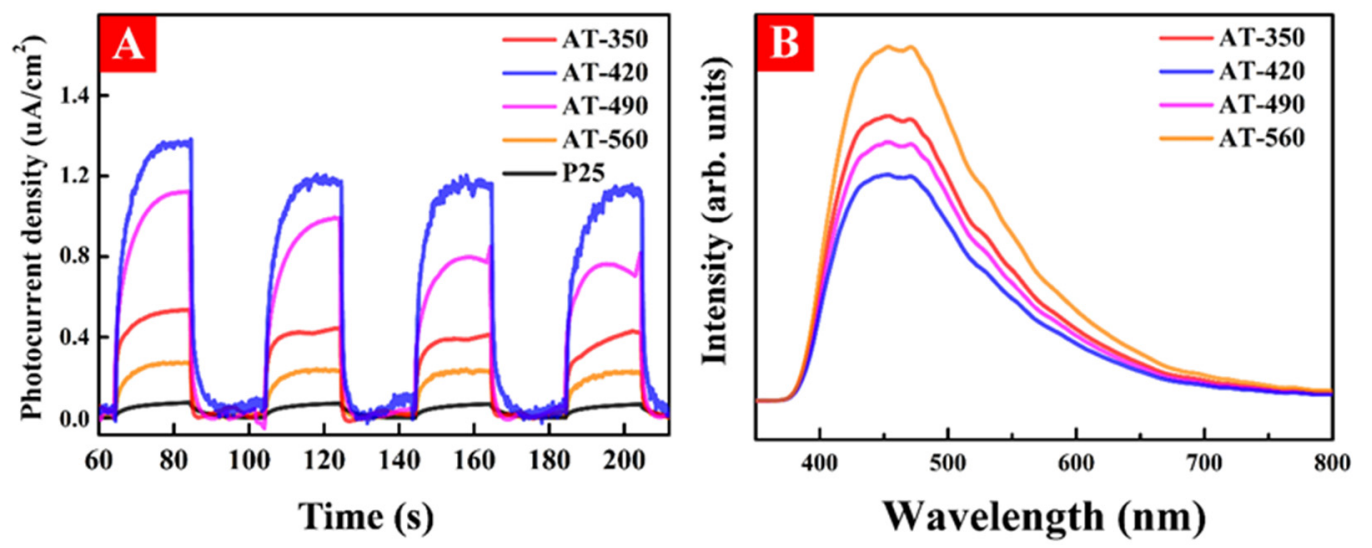

Figure 7. (A) The transient photocurrent density and (B) photoluminescence spectra for all samples.

\subsection{The Visible-Light-Driven Photodegradation of $\mathrm{HAm}-\mathrm{TiO}_{2-x}$ and Its Coatings}

The visible-light photoactivity of $\mathrm{HAm}-\mathrm{TiO}_{2-x}$ was evaluated by $\mathrm{RhB}$ photodegradation, shown in Figure 8A. During the dark adsorption, nearly $27.3 \%$ of RhB was removed by adsorption. AT-420 displayed the best performance among these samples, such that RhB photodegradation was accomplished within 20 min, owing to the fact that surface/subsurface $\mathrm{O}_{\mathrm{V}}$ is generally considered unstable in air and water by the ambient oxidation, leading to faded photoactivity. Herein, to check the stability, AT-420 was put into deionized water for 7 days under ambient conditions for the aging test. Obviously, there was no clear difference between each round when using the aged AT-420 shown in Figure $8 \mathrm{~B}$, which proves that this surface/subsurface $\mathrm{O}_{\mathrm{V}}$ in $\mathrm{HAm}-\mathrm{TiO}_{2-\mathrm{x}}$ was rather stable. In order to extend applications under various complicated environments, photocatalyst nanoparticles were usually deposited on diverse substrates, including glass, plastic film, and fiber. Herein, we urged the use of photocatalytic coating that has highly visible-light driven self-cleaning performance. We deposited $\mathrm{HAm}_{-} \mathrm{TiO}_{2-x}$ nanoparticles on glass $\left(\mathrm{HAm}-\mathrm{TiO}_{2-\mathrm{x}} @\right.$ glass, $\left.10 \times 5 \times 0.3 \mathrm{~cm}^{3}\right)$, which displayed an excellent photocatalytic self-cleaning performance when decomposing the dyes. As shown in Figure 8C, apart from the remaining high concentration "coffee ring" of RhB, most of the area became clean again. In addition, the visible-light photodegradation of methylene blue (MB) was also performed using the coated glass $\left(2 \times 2 \times 0.3 \mathrm{~cm}^{3}\right)$, as shown in Figure 8D, displaying a complete degradation of $\mathrm{MB}$ pollution. Therefore, according to the above polluted water photodegradation experiments, both $\mathrm{HAm}_{-} \mathrm{TiO}_{2-x}$ nanoparticles and its coatings enjoyed high visible photoactivity. Moreover, to detect $\cdot \mathrm{OH}$ and $\cdot \mathrm{O}_{2}{ }^{-}$, EPR spin trapping experiments were employed over AT-420, with visible-light irradiation. As observed in Figure 8E, obvious signals of DMPO-OH and DMPO- $\mathrm{O}_{2}{ }^{-}$confirmed that $\cdot \mathrm{OH}$ and $\cdot \mathrm{O}_{2}{ }^{-}$were the dominant active oxygen species during photodegradation. Notably, the quantity of $\cdot \mathrm{O}_{2}{ }^{-}$was as much as seven times larger than that of $\cdot \mathrm{OH}$ listed in Table S1, which was generated by the surface $\mathrm{O}_{\mathrm{V}}$-absorbed electrons and which, simultaneously, verified the large quantities of surface/subsurface $\mathrm{O}_{\mathrm{V}}$. Actually, except for $\cdot \mathrm{OH}$ and $\cdot \mathrm{O}_{2}{ }^{-}$, various reactive species, including $\cdot \mathrm{OH}_{\mathrm{ads}}\left(\cdot \mathrm{OH}\right.$ absorbed on the catalyst surface), photoinduced holes $\left(\mathrm{h}^{+}\right)$, electrons, as well as $\mathrm{H}_{2} \mathrm{O}_{2}$, also participated during the photodegradation process. To explore the contribution from these reactive species, the trapping experiments were carried out over AT-420 using visible-light irradiation. Five kinds of scavengers, including AO, Fe(II)-EDTA, $\mathrm{KI}, \mathrm{BQ}$, and IPA were used to probe $\mathrm{h}^{+}, \mathrm{H}_{2} \mathrm{O}_{2}, \mathrm{OH}_{\mathrm{ads}}$ and electron, $\cdot \mathrm{O}_{2}{ }^{-}$, and $\cdot \mathrm{OH}$ in the bulk solution, respectively [50]. As shown in Figure 8F, the visible-light photodegradation rate without scavenger was $95.9 \%$, while, in the presence of AO, Fe(II)-EDTA, KI, BQ, and IPA were $94.1 \%, 12.2 \%, 11.3 \%, 17.8$, and $95.3 \%$, respectively. It was, thus, confirmed that $\cdot \mathrm{OH}_{\text {ads }}, \cdot \mathrm{O}_{2}{ }^{-}$, and $\mathrm{H}_{2} \mathrm{O}_{2}$ were the dominated reactive species that contributed to high visible-light photoactivity, which is in good accordance with the EPR spin trapping results. However, $\mathrm{h}^{+}$and $\cdot \mathrm{OH}$ in the bulk solution had almost no influence on photoactivity, which demonstrated that the generation of $\mathrm{h}^{+}$was invalidated by preventing the transition of 
electrons from the valence band to the conduction band or the $\mathrm{O}_{\mathrm{V}}$ defect band, and was consistent with the band structures results, shown in Figure 5. The recycling experiment using AT-420 under visible light was carried out; the structural changes of the catalyst after usage are seen in Figure S5. Finally, the surface appearance of $\mathrm{HAm}-\mathrm{TiO}_{2-\mathrm{x}} @$ glass was characterized by SEM, as seen in Figure 8G. According to 1- $\mu$ m magnification SEM image, $\mathrm{HAm}-\mathrm{TiO}_{2-x}$ nanoparticles were uniformly coated on the glass surface, and the EDS mapping with 25- $\mu \mathrm{m}$ magnification also proved that Ti element was uniformly distributed on the glass surface. Increasing surface uniformity of $\mathrm{HAm}-\mathrm{TiO}_{2-x}$ nanoparticles can contribute to its photocatalytic activity. Due to the distribution of $\mathrm{HAm}^{-\mathrm{TiO}_{2-x}}$ nanoparticles, the $\mathrm{HAm}-\mathrm{TiO}_{2-x}$ on the glass showed superhydrophilicity, which could increase the contact area between the catalyst and pollutant molecules, and which, thus, improved the photodegradation performance.

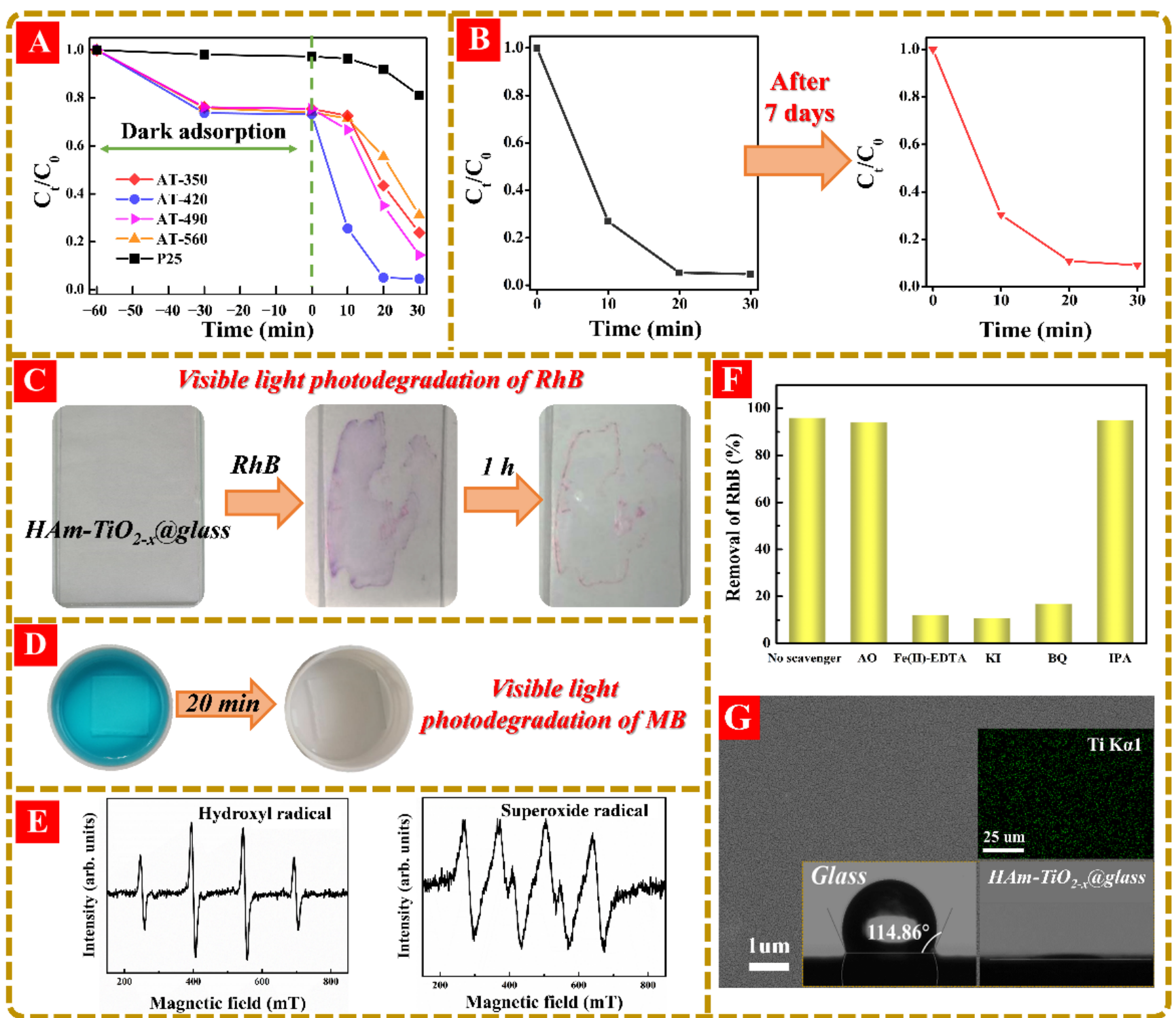

Figure 8. (A) The visible-light photodegradation of RhB for all samples and (B) the visible-light photodegradation stability test for AT-420. The visible-light photodegradations of (C) RhB and (D) $\mathrm{MB}$ using $\mathrm{HAm}-\mathrm{TiO}_{2-x}$ coated glass. (E) The EPR detection of $\cdot \mathrm{O}_{2}{ }^{-}$and $\cdot \mathrm{OH}$ over AT-420 under visible-light illumination. (F) The removal rates of AT-420 in the presence of different scavenging species. (G) Large-view SEM picture of $\mathrm{HAm}_{-} \mathrm{TiO}_{2-\mathrm{x}}$ coated glass, the EDS mapping of Ti element and the hydrophilicity test in $\mathrm{HAm}-\mathrm{TiO}_{2-x}$ coated glass were shown in the inset. 


\subsection{The HCHO Photodegradation Activity under Ambient Environment}

To investigate the formaldehyde $(\mathrm{HCHO})$ photodegradation efficiency under ambient environment, a sealed box $\left(1 \times 1 \times 1 \mathrm{~m}^{3}\right)$ was used with simulated indoor conditions inside the box, including low $\mathrm{HCHO}$ concentration $(\sim 0.6 \mathrm{ppm})$, air atmosphere, indoor temperature $\left(\sim 25^{\circ} \mathrm{C}\right)$, relative humidity $(\mathrm{RH}=45 \%)$, and low-power-density irradiation $\left(\lambda=600 \mathrm{~nm}, 0.136 \mathrm{~mW} / \mathrm{cm}^{2}\right)$. As shown in Figure $9 \mathrm{~A}, \mathrm{HAm}-\mathrm{TiO}_{2-\mathrm{x}}$ coating was put in the box for 1-h dark adsorption; the $\mathrm{HCHO}$ concentrations decreased slightly in the presence of all samples. During the visible light irradiation $(0-18 \mathrm{~h})$, gradual $\mathrm{HCHO}$ photodegradations were observed and followed a rank: AT-560 < AT-350 < AT-490 < AT-420, which also obeyed the rank of subsurface $\mathrm{O}_{\mathrm{V}}$ concentration, as shown in PAS results. As an experimental comparison under the same condition, the $\mathrm{HCHO}$ concentration only decreased to $0.55 \mathrm{ppm}$ using $\mathrm{P} 25 \mathrm{TiO}_{2}$, owing to its poor visible light photodegradation. Notably, the final $\mathrm{HCHO}$ concentrations with AT-420 and AT- 490 were both lower than $0.08 \mathrm{ppm}$, which is the international standard $\mathrm{HCHO}$ level for an indoor environment [51]. As shown in Figure 9B, the $\mathrm{HCHO}$ conversion efficiency increased rapidly in the initial stage of $0-4 \mathrm{~h}$ but reached saturation during 6-18 h; AT- 420 exhibited the highest conversion efficiency of $92.62 \%$ (inset) among these samples. To verify the stability of HCHO photodegradation, a sustained release formaldehyde source was put in the box. As displayed in Figure 9C, the $\mathrm{HCHO}$ concentration linearly increased and, finally, reached $0.8 \mathrm{ppm}$ in the absence of $\mathrm{HAm}-\mathrm{TiO}_{2-\mathrm{x}}$. When AT-420 coating was put in the box, the HCHO concentration, as comparation, sharply increased during the $0-100 \mathrm{~min}$, but trended to a steady value of $0.2 \mathrm{ppm}$ with the increasing time, which suggested that a balance between the $\mathrm{HCHO}$ release and the photodegradation was achieved. More importantly, there was no upward tendency of $\mathrm{HCHO}$ concentration, demonstrating the strong and stubborn photoactivity of $\mathrm{HAm}-\mathrm{TiO}_{2-x}$ that can erase the accumulation of $\mathrm{HCHO}$ and its by-products on catalyst surface. In addition, UV light of $365 \mathrm{~nm}$ assisted $\mathrm{HCHO}$ photodegradation, which was carried out using AT-420 coating, as shown in Figure 9D, which unexpectedly displayed poor photoactivity. Furthermore, the AQYs of $\mathrm{HCHO}$ photodegradation with different wavelengths of light were measured using AT-420 coating, as shown in Figure 9E. With the 600-nm light source, the AQY in the beginning of $0-2 \mathrm{~h}$ was nearly $3 \times 10^{-4} \%$ but decreased gradually during $3-18 \mathrm{~h}$ and reached $0.6 \times 10^{-4} \%$ eventually. While, with the 365-nm light source, the AQY exhibited a similar change tendency but was much lower than that of the $600-\mathrm{nm}$ light source. Finally, relative humidity, as an important factor that affects $\mathrm{HCHO}$ photodegradation, should be explored. As displayed in Figure 9F, when $\mathrm{RH}$ during the visible-light photodegradation over AT- 420 was 35\%, the $\mathrm{HCHO}$ elimination efficiency was $80.7 \%$. When increasing RH from $35 \%$ to $61 \%$, the elimination efficiency was also enhanced from $80.7 \%$ to $98.3 \%$, which could be ascribed to the adsorbed $\mathrm{H}_{2} \mathrm{O}$ on $\mathrm{HAm}-\mathrm{TiO}_{2-x}$ that contributed to the generation of $\cdot \mathrm{OH}$ radical. When $\mathrm{RH}$ arrived at $73 \%$, the $\mathrm{HCHO}$ decomposition efficiency, however, decreased to $88.7 \%$, which should be a result of the competitive adsorption between $\mathrm{H}_{2} \mathrm{O}$ and $\mathrm{HCHO}$. Given the above results, $\mathrm{HAm}-\mathrm{TiO}_{2-\mathrm{x}}$ showed high and stable performance in $\mathrm{HCHO}$ photocatalytic elimination under the simulated indoor environment. 


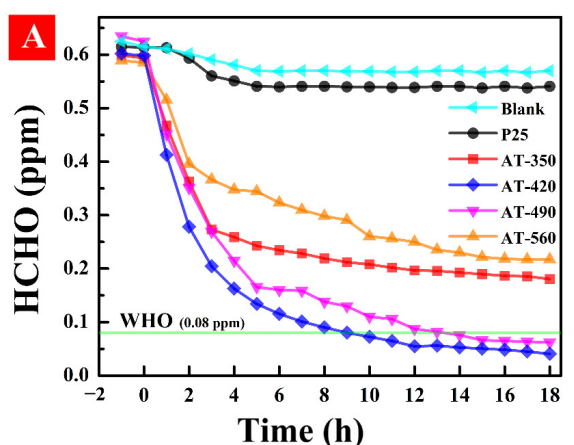

Time (h)

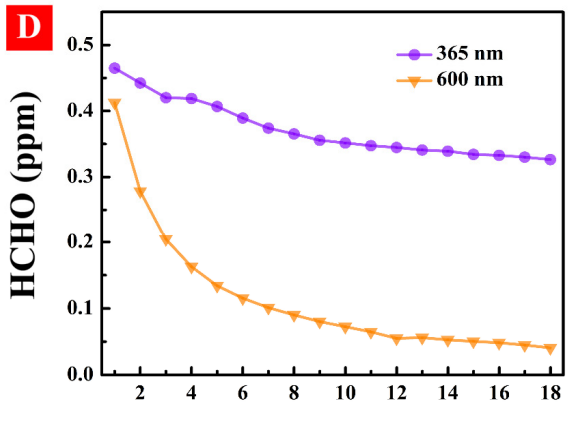

Time (h)
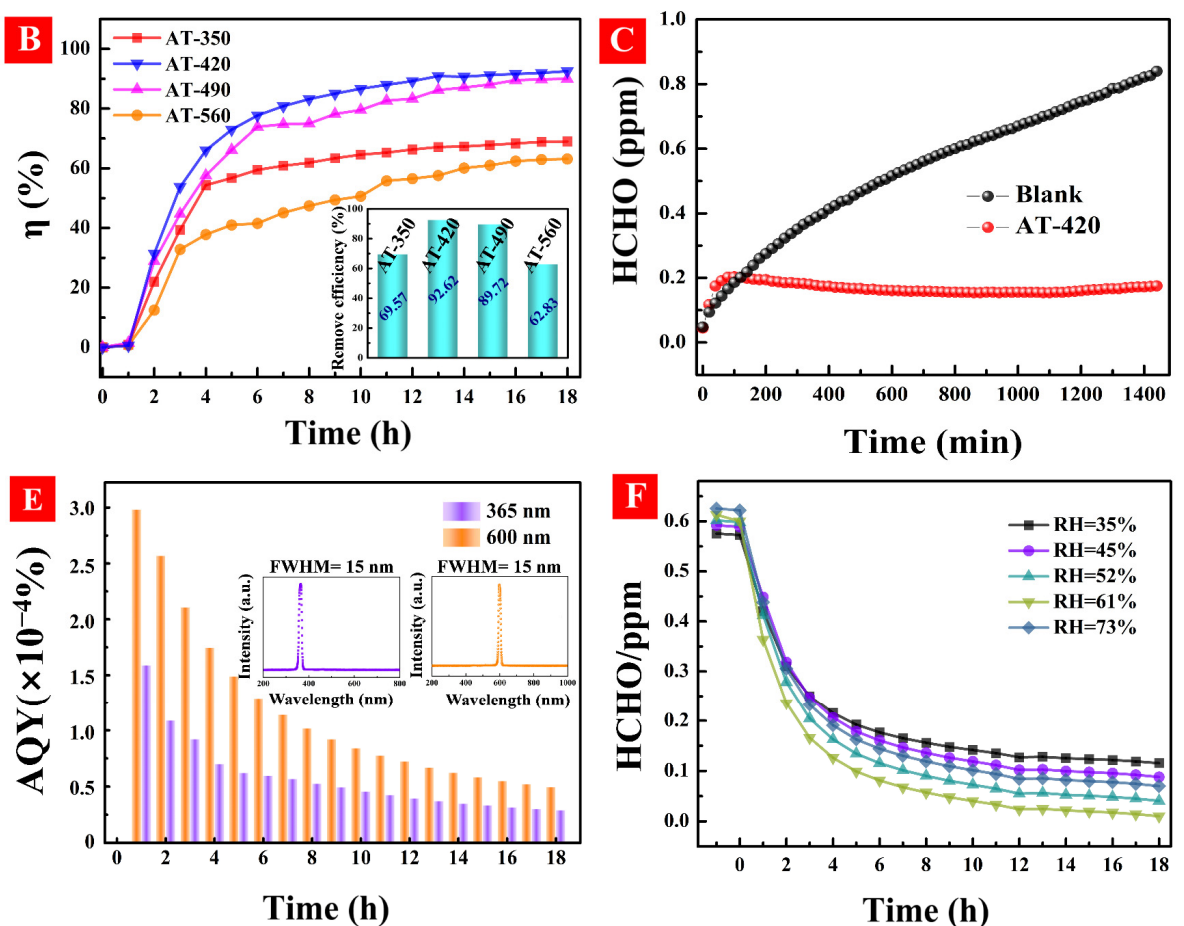

Figure 9. (A) Visible-light formaldehyde photodegradation and (B) the conversion efficiency with different samples, and the inset was the remove efficiency for all samples. (C) Durable test of AT-420 under simulated indoor conditions. (D) The HCHO photodegradations under 365-nm and 600-nm light sources using AT-420 sample. (E) The AQY of formaldehyde photodegradation with different wavelength light using AT-420 coating, and the inset were the spectra of UV ( $365 \mathrm{~nm}, \mathrm{FWHM}=15 \mathrm{~nm})$ and visible $(600 \mathrm{~nm}, \mathrm{FWHM}=15 \mathrm{~nm})$ light. (F) The effect of relative humidity for AT-420 coating using 600-nm light source.

3.7. Investigations on the Surface Reaction Pathway and HCHO Adsorption Mechanism with the Subsurface $\mathrm{O}_{V}$

In-situ DRIFTS analysis was employed to dynamically investigate the reaction pathways of $\mathrm{HCHO}$ photodegradation on $\mathrm{HAm}_{-} \mathrm{TiO}_{2-x}$ surface. As shown in Figure 10, the peaks at 1157 and $1200 \mathrm{~cm}^{-1}$ were identified as HCHO [52,53]; the peaks at 1040, 1260, 1400 , and $1633 \mathrm{~cm}^{-1}$ were ascribed to carbonate species [54-57]; the peak at $1225 \mathrm{~cm}^{-1}$ was considered as a formate species [58], while the peak at $3390 \mathrm{~cm}^{-1}$ was considered as surface $\mathrm{Ti}-\mathrm{OH}$ [23]. Observably, with the increasing irradiation time, the concentrations of all reactants, including formaldehyde, carbonate species, formate species, and surface hydroxyl groups were increased, suggesting that formaldehyde was absorbed on the $\mathrm{HAm}^{-\mathrm{TiO}_{2}-\mathrm{x}}$ surface and oxidized by hydroxyl radicals into formate species and carbonate species. The main intermediates were carbonate species, which suggested the fast oxidation of $\mathrm{HCHO}$ and formate species. Thus, we inferred two potential photo-decompose paths of $\mathrm{HCHO} \rightarrow$ $\mathrm{HCOOH} \rightarrow \mathrm{H}_{2} \mathrm{CO}_{3} \rightarrow \mathrm{CO}_{2}$, and $\mathrm{HCHO} \rightarrow \mathrm{HCOOH} \rightarrow \mathrm{CO}_{2}$. Unexpectedly, photocatalyst inactivation by this accumulated carbonate species and formate species did not occur, which was proven by the enhancement of surface hydroxyl groups with time. In light of these results and discussion, it was, thus, concluded that $\mathrm{HAm}_{-} \mathrm{TiO}_{2-x}$ possessed a straightforward reaction pathway and relevant strong photoactivity in $\mathrm{HCHO}$ photodegradation. 


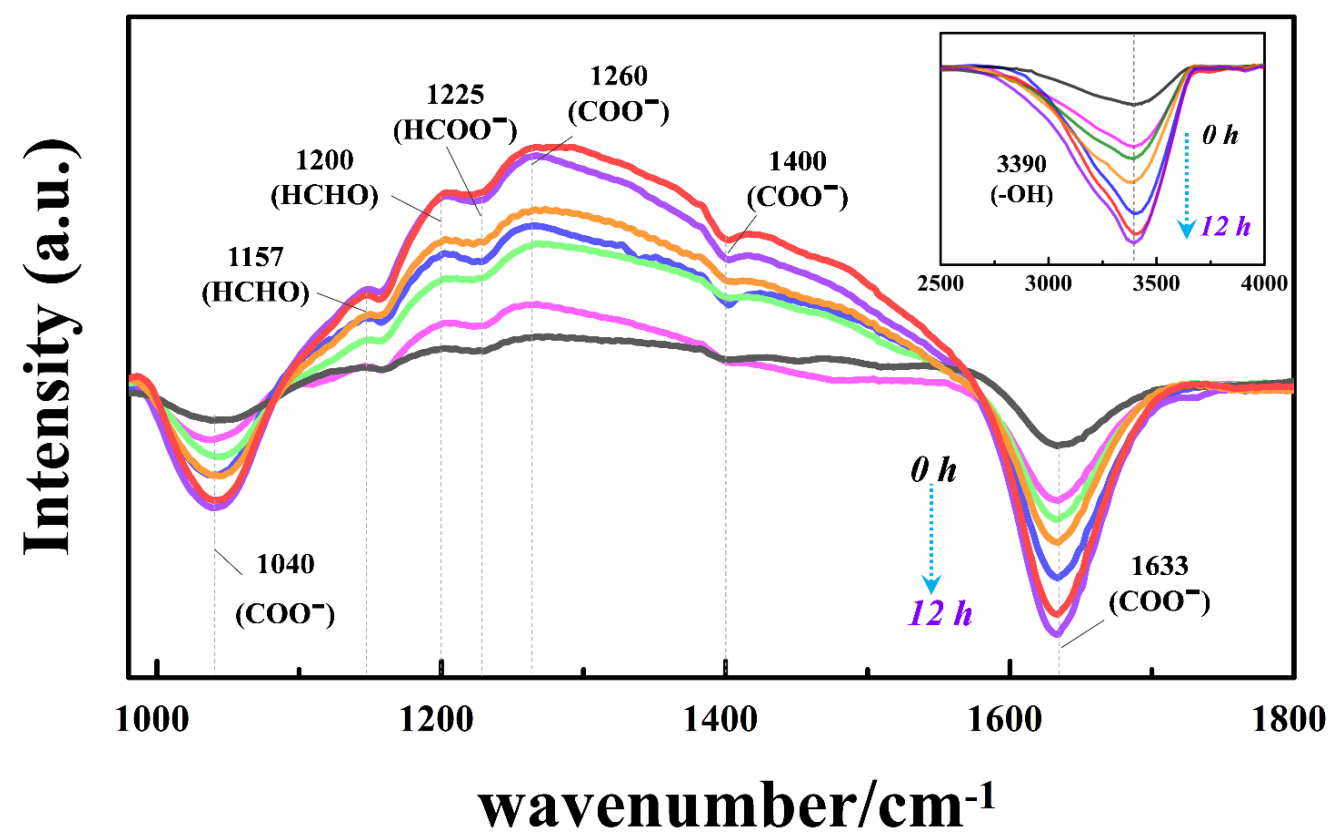

Figure 10. In-situ DRIFTS of AT-420 during the visible-light photodegradation of HCHO.

Generally, the photodegradation of $\mathrm{HCHO}$ is assumed to be determined by the synergistic effect of light absorption, photocarriers migration, reactants adsorption, and reaction pathway. Based on the aforementioned characterization results and discussion, HAm$\mathrm{TiO}_{2-x}$ exhibited high performances in visible-light absorption, e-h pairs migration, and straightforward reaction pathways. Herein, reactants adsorption and, especially, the effect of surface hydroxyl group and $\mathrm{O}_{\mathrm{V}}$ on chemisorb capability of $\mathrm{HCHO}$ and $\mathrm{O}_{2}$, should be revealed. Here, we constructed two kinds of DFT-simulated adsorption models, including $\mathrm{HAm}-\mathrm{TiO}_{2-\mathrm{x}}-\mathrm{OH}$ (the effect of surface hydroxyl group) and $\mathrm{HAm}-\mathrm{TiO}_{2-\mathrm{x}}-\mathrm{O}_{\mathrm{V}}$ (the effect of subsurface $\mathrm{O}_{\mathrm{V}}$ ) to investigate $\mathrm{HCHO}$ adsorption (Figure $11 \mathrm{~A}$ ) and $\mathrm{O}_{2}$ adsorption (Figure 11B). Based on the DFT models, the adsorption energies of $\mathrm{O}_{2}$ and $\mathrm{HCHO}$ on the surfaces of anatase $\mathrm{TiO}_{2}, \mathrm{HAm}-\mathrm{TiO}_{2-\mathrm{x}}-\mathrm{OH}$, and $\mathrm{HAm}-\mathrm{TiO}_{2-\mathrm{x}}-\mathrm{O}_{\mathrm{V}}$ are exhibited in Figure $11 \mathrm{C}$. Anatase $\mathrm{TiO}_{2}$ showed the adsorption energies of $-0.43 \mathrm{eV}\left(\mathrm{O}_{2}\right)$ and $-0.81 \mathrm{eV}$ $(\mathrm{HCHO})$. When using $\mathrm{HAm}-\mathrm{TiO}_{2-x}-\mathrm{OH}$, a lower adsorption energy of $\mathrm{O}_{2}(-0.75 \mathrm{eV})$ and $\mathrm{HCHO}(-0.98 \mathrm{eV})$ were obtained. As for $\mathrm{HAm}-\mathrm{TiO}_{2-\mathrm{x}}-\mathrm{O}_{\mathrm{V}}$, the corresponding adsorption energies were sharply decreased to -1.42 and $-1.58 \mathrm{eV}$. Therefore, adsorption capabilities of $\mathrm{O}_{2}$ and $\mathrm{HCHO}$ in $\mathrm{HAm}-\mathrm{TiO}_{2-\mathrm{x}}$ were both largely promoted in the presence of subsurface $\mathrm{O}_{\mathrm{V}}$, which could significantly promote the capturing of $\mathrm{HCHO}$ on the $\mathrm{HAm}-\mathrm{TiO}_{2-\mathrm{x}}$ photocatalyst and improve the $\mathrm{HCHO}$ photodegradation efficiency. 


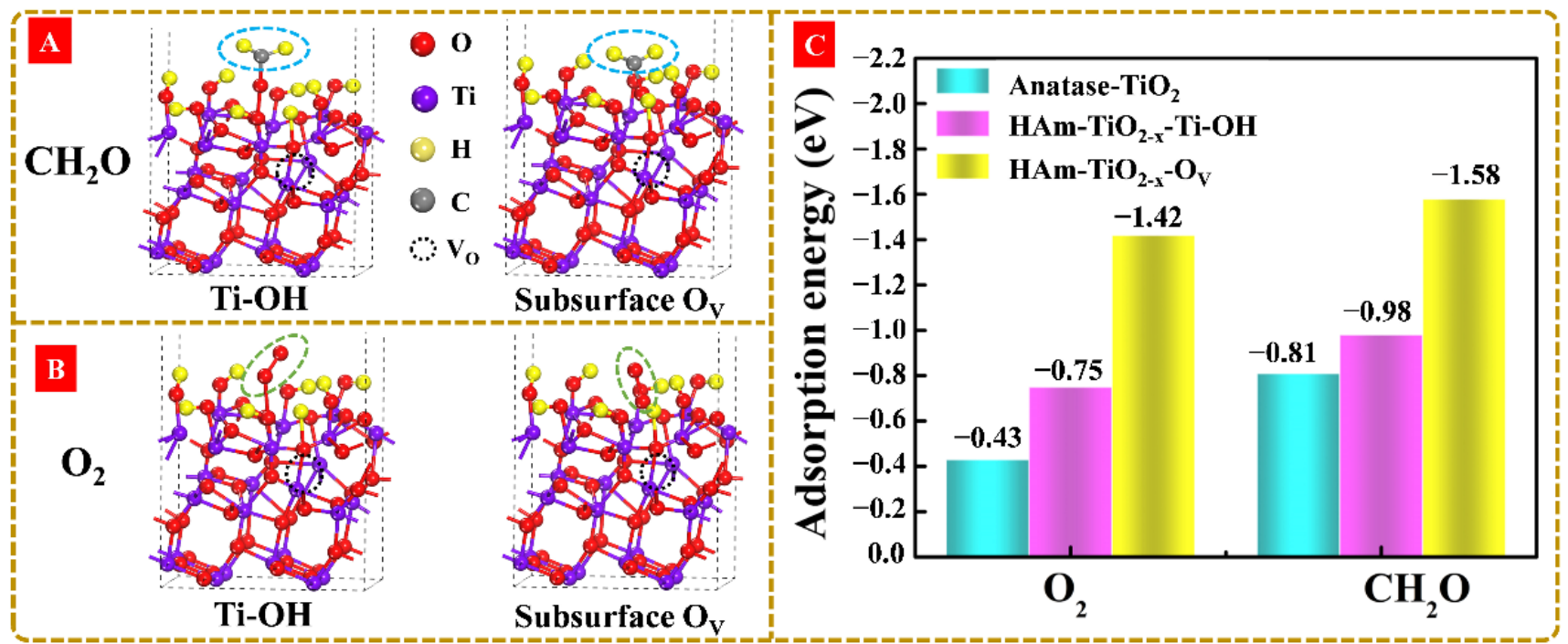

Figure 11. The adsorption models of (A) formaldehyde and (B) oxygen in the presence of surface hydroxyl groups and subsurface $\mathrm{O}_{V}$, respectively. (C) The adsorption energies of $\mathrm{O}_{2}$ and $\mathrm{HCHO}$ over anatase $\mathrm{TiO}_{2}, \mathrm{HAm}-\mathrm{TiO}_{2-\mathrm{x}}-\mathrm{OH}$, and $\mathrm{HAm}-\mathrm{TiO}_{2-\mathrm{x}}-\mathrm{O}_{\mathrm{V}}$.

\subsection{The Mechanism of $\mathrm{HCHO}$ Photocatalysis and $\mathrm{O}_{V}$ Generation over $\mathrm{HAm}-\mathrm{TiO}_{2-x}$}

Based on the above results and discussions, the photocatalysis mechanism of HCHO purification with $\mathrm{HAm}_{-} \mathrm{TiO}_{2-\mathrm{x}}$ was illustrated in Figure 12. The refined electrical structure of $\mathrm{HAm}-\mathrm{TiO}_{2-\mathrm{x}}$ followed the band structures of the Subsurface- $4 \mathrm{O}_{\mathrm{V}}$ model, as mentioned in Figure 6e, which generated deep trap states close to the conduction band. When solar light irradiation - which has large effective mass-owing to the $\mathrm{O}_{\mathrm{V}}$-induced midgap trap states, restricts charge mobility, electrons from valence states are hardly transferred from valence band to $\mathrm{O}_{\mathrm{V}}$-induced deep states or conduction band, leading to bad photoactivity in the $\mathrm{UV}$ region. Visible-light capture in $\mathrm{HAm}^{-\mathrm{TiO}_{2-x}}$ is mainly originated from $\mathrm{O}_{\mathrm{VS}}-\mathrm{CB}$ transition, as mentioned in Figure 6. To some extent, $\mathrm{HAm}-\mathrm{TiO}_{2-\mathrm{x}}$, with its self-doped $\mathrm{O}_{\mathrm{V}}$ defects was, thus, customized for long-wavelength response photocatalysis. On the other hand, with the benefits of abundant surface $\mathrm{O}_{\mathrm{V}}$, photoinduced electrons had high separation efficiency and long lifetime, resulting in directional migration from the inner lattice to the top surface. Localized surface $\mathrm{O}_{\mathrm{V}}$ accumulated a considerable number of electrons to react with $\mathrm{O}_{2}$ and $\mathrm{H}_{2} \mathrm{O}$ to form $\cdot \mathrm{O}_{2}{ }^{-}$and $\cdot \mathrm{OH}$, which can rapidly decompose the adsorbed $\mathrm{HCHO}$ into $\mathrm{CO}_{2}, \mathrm{H}_{2} \mathrm{O}$, and intermediates such as $\mathrm{HCOOH}$ and $\mathrm{H}_{2} \mathrm{CO}_{3}$. Moreover, contributed by subsurface $\mathrm{O}_{\mathrm{V}}$ and surface hydroxyl radical $(\cdot \mathrm{OH})$, chemisorb energy of $\mathrm{HAm}-\mathrm{TiO}_{2-x}$ was much lower than that of crystalline anatase $\mathrm{TiO}_{2}$, resulting in the boosted adsorption capability of $\mathrm{HCHO}$.

Finally, the formation mechanism of $\mathrm{HAm}-\mathrm{TiO}_{2-x}$ nanoparticles should be clarified. In fact, apart from the generation of hydrogen atoms, liquid plasma discharge also produces many kinds of oxidative species including superoxide anion radicals, electrons, hydroxyl radical, hydrogen peroxide, and ultraviolet radiation, which enables strong oxygenation in electrolyte $[59,60]$. Herein, liquid plasma discharge involved two contrasting effects: liquid plasma hydrogenation and oxidation. Whether hydrogenation or oxidation dominates the whole reaction depends on the output power. Typically, hydrogenation plays a major role at a lower output power. With a proper increase of output power, hydrogenation is simultaneously enhanced and governs the reaction, but, when output power further increases and reaches a threshold, oxidation beyond hydrogenation dominates the whole reaction. In our case, compared with AT-350, a stronger hydrogenation effect was achieved with AT-420 (Figure S1), which resulted in a much higher $\mathrm{O}_{\mathrm{V}}$ concentration. By further increasing output power (AT-420 to AT-560), surface $\mathrm{O}_{\mathrm{V}}$ concentration declined, which could be due to the leading role of liquid plasma oxidation over the process. As a result, this alternate effect of hydrogenation and oxidation could also account for the "round-trip" 
occurrence of $\mathrm{O}_{\mathrm{V}}$ in $\mathrm{HAm}-\mathrm{TiO}_{2-\mathrm{x}}$, as well as the rank of subsurface $\mathrm{O}_{\mathrm{V}}$ concentration, listed as AT-560 < AT-350 < AT-490 < AT-420 (as seen in PAS and XPS data).

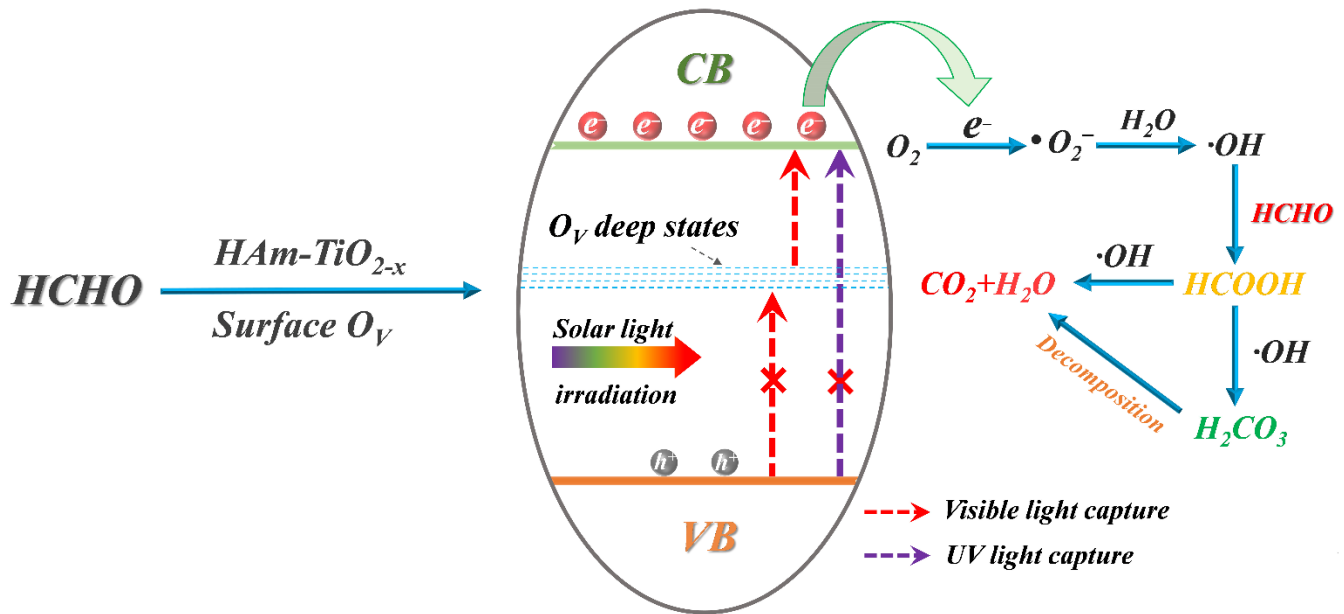

Figure 12. The proposed mechanism for photocatalytic elimination of $\mathrm{HCHO}$ with $\mathrm{HAm}-\mathrm{TiO}_{2-\mathrm{x}}$.

\section{Conclusions}

In this work, hydrogenated amorphous $\mathrm{TiO}_{2-x}$ with high surface area $\left(176.7 \mathrm{~cm}^{2} \mathrm{~g}^{-1}\right)$ was successfully prepared using a liquid plasma-induced hydrogenation strategy. The effect of surface $\mathrm{O}_{\mathrm{V}}$ engineering on the physico-chemical properties of amorphous $\mathrm{TiO}_{2}$ photocatalyst and, in particular, the manipulation of $\mathrm{O}_{\mathrm{V}}$ concentration and distribution on its electrical structure, was revealed. The optical and electrical properties of $\mathrm{HAm}^{-\mathrm{TiO}_{2-\mathrm{x}}}$ were affected by the surface $\mathrm{O}_{\mathrm{V}}$ engineering, which could be directly regulated by controlling the output power of liquid plasma. Subsurface $\mathrm{O}_{\mathrm{V}}$, rather than surface $\mathrm{O}_{\mathrm{V}}$, induced a disordered surface, which accounted for the narrow bandgap $(2.36 \mathrm{eV})$ by introducing deep trap states under a conduction band $(0.5 \mathrm{eV})$. With the advantages of strong visible-light capture and efficient photocarriers transferring, $\mathrm{HAm}-\mathrm{TiO}_{2-\mathrm{x}}$ and its coatings exhibited strong visible-light photodegradation of polluted water. Furthermore, $\mathrm{HAm}-\mathrm{TiO}_{2-\mathrm{x}}$ was employed to decompose low-concentration formaldehyde under severe indoor environments. Investigations on the surface reaction pathway and formaldehyde adsorption mechanism with the subsurface $\mathrm{O}_{V}$ were also carried out. We found that subsurface $\mathrm{O}_{V}$ in $\mathrm{HAm}_{-} \mathrm{TiO}_{2-x}$ could significantly enhance the adsorption energy of $\mathrm{HCHO}(-1.58 \mathrm{eV})$ and $\mathrm{O}_{2}(-1.42 \mathrm{eV})$, compared with anatase $\mathrm{TiO}_{2}$. Based on large amounts of $\cdot \mathrm{OH}$ radicals and strong chemiadsorption capability, $\mathrm{HAm}^{-\mathrm{TiO}_{2-\mathrm{x}}}$ showed high quantum efficiency of $3 \times 10^{-6}$ molecules / photon and photoactivity of $92.6 \%$ under visible light $(\lambda=600 \mathrm{~nm})$. Sustaining growth of surface $\cdot \mathrm{OH}$ radicals guaranteed long-term photocatalytical stability

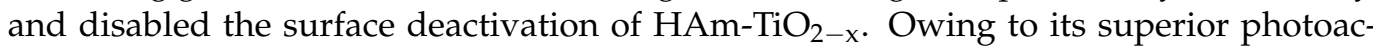
tivity, extremely low cost, and simple preparation technology, hydrogenated amorphous $\mathrm{TiO}_{2-x}$ could be suitable for large production to apply in some practical photocatalytic environment purifications in the future.

Supplementary Materials: The following supporting information can be downloaded at: https: / / www.mdpi.com/article/10.3390/nano12050742/s1, Figure S1: The emission spectrum of liquid plasma with different output power, (A-D) are obtained by applying the output power of 350, 420, 490, and $560 \mathrm{~W}$, respectively, Figure S2: Raman spectra of all $\mathrm{HAm}^{-\mathrm{TiO}_{2-x}}$ samples, Figure S3: (A-D) were the Kubelka Munk graphs of AT-350 (2.64 eV), AT-420 (2.24 eV), AT-490 (2.51 eV), and AT-560 $(2.89 \mathrm{eV})$, respectively, Figure S4: X-ray photoelectron spectroscopy valence band spectra of all samples, Figure S5: (A) The recycling experimental of RhB using AT-420 under visible light. $(B, C)$ were EPR and XRD data for AT-420 and catalyst after recycling reaction, respectively. (D) High resolution TEM image of AT-420 after recycling reaction, and the disordered surface was marked with yellow dashed line, Table S1: The amount of $\cdot \mathrm{O}_{2}{ }^{-}$and $\cdot \mathrm{OH}$ by employing of 5,5-dimethyl-1pyrroline- $\mathrm{N}$-oxide (DMPO) to in-situ trap the spin-reactive species. 


\begin{abstract}
Author Contributions: G.F.: experimental measurements, material fabrication, manuscript preparation. B.W.: theoretical simulation, and manuscript reviewing. M.H., S.Y., Y.L. and S.S.: experiments and project discussions. H.Z.: photocatalyst design and experiments, project supervision, manuscript writing and reviewing. All authors have read and agreed to the published version of the manuscript.

Funding: This work was granted by National Key Research and Development Program of China (2018YFB0504400), National Natural Science Fund of China (11621404, 11727812, and 62035005), and Shanghai Science and Technology Commission (2019SHZDZX01-ZX06).
\end{abstract}

Institutional Review Board Statement: Not applicable.

Informed Consent Statement: Not applicable.

Data Availability Statement: The data presented in this study are available on request from the corresponding author. The data are not publicly available due to the reason that the data also forms part of an ongoing study.

Acknowledgments: This work was granted by National Key Research and Development Program of China (2018YFB0504400), National Natural Science Fund of China (11621404, 11727812, and 62035005), and Shanghai Science and Technology Commission (2019SHZDZX01-ZX06).

Conflicts of Interest: The authors declare no conflict of interest.

\title{
References
}

1. Fujishima, A.; Rao, T.N.; Tryk, D.A. Titanium dioxide photocatalysis. J. Photoch. Photobiol. C 2000, 1, 1-21. [CrossRef]

2. Rao, Z.; Lu, G.; Mahmood, A.; Shi, G.; Xie, X.; Sun, J. Deactivation and activation mechanism of $\mathrm{TiO}_{2}$ and $\mathrm{rGO}^{-\mathrm{Er}^{3+}-\mathrm{TiO}} 2 \mathrm{during}$ flowing gaseous VOCs photodegradation. Appl. Catal. B Environ. 2021, 284, 119813. [CrossRef]

3. Daghrir, R.; Drogui, P.; Robert, D. Modified $\mathrm{TiO}_{2}$ for environmental photocatalytic applications: A review. Ind. Eng. Chem. Res. 2013, 52, 3581-3599. [CrossRef]

4. Luciani, G.; Imparato, C.; Vitiello, G. Photosensitive hybrid nanostructured materials: The big challenges for sunlight capture. Catalysts 2020, 10, 103. [CrossRef]

5. Janczarek, M.; Endo-Kimura, M.; Raja-Mogan, T.; Kowalska, E. The role of oxygen vacancy and other defects for activity enhancement. In Green Photocatalytic Semiconductors: Recent Advances and Applications; Garg, S., Chandra, A., Eds.; Springer International Publishing: Cham, Switzerland, 2022; pp. 337-355.

6. Hao, L.; Huang, H.; Zhang, Y.; Ma, T. Oxygen vacant semiconductor photocatalysts. Adv. Funct. Mater. 2021, $31,2100919$. [CrossRef]

7. Zhang, Y.; Xu, Z.; Li, G.; Huang, X.; Hao, W.; Bi, Y. Direct observation of oxygen vacancy self-healing on TiO 2 photocatalysts for solar water splitting. Angew. Chem. Int. Edit. 2019, 58, 14229-14233. [CrossRef]

8. Li, J.; Zhang, M.; Guan, Z.; Li, Q.; He, C.; Yang, J. Synergistic effect of surface and bulk single-electron-trapped oxygen vacancy of $\mathrm{TiO}_{2}$ in the photocatalytic reduction of $\mathrm{CO}_{2}$. Appl. Catal. B Environ. 2017, 206, 300-307. [CrossRef]

9. Lin, L.; Ma, Y.; Wu, J.; Pang, F.; Ge, J.; Sui, S.; Yao, Y.; Qi, R.; Cheng, Y.; Duan, C.; et al. Origin of photocatalytic activity in Ti ${ }^{4+} / \mathrm{Ti}^{3+}$ core-shell titanium oxide nanocrystals. J. Phys. Chem. C 2019, 123, 20949-20959. [CrossRef]

10. Mao, J.; An, X.; Gu, Z.; Zhou, J.; Liu, H.; Qu, J. Visualizing the interfacial charge transfer between photoactive microcystis aeruginosa and hydrogenated $\mathrm{TiO}_{2}$. Environ. Sci. Technol. 2020, 54, 10323-10332. [CrossRef]

11. Li, J.; Weng, B.; Cai, S.; Chen, J.; Jia, H.; Xu, Y. Efficient promotion of charge transfer and separation in hydrogenated $\mathrm{TiO}_{2} / \mathrm{WO}_{3}$ with rich surface-oxygen-vacancies for photodecomposition of gaseous toluene. J. Hazard. Mater. 2018, 342, 661-669. [CrossRef]

12. Yan, Y.; Cheng, X.; Zhang, W.; Chen, G.; Li, H.; Konkin, A.; Sun, Z.; Sun, S.; Wang, D.; Schaaf, P. Plasma hydrogenated TiO 2 /Nickel foam as an efficient bifunctional electrocatalyst for overall water splitting. ACS Sustain. Chem. Eng. 2019, 7, 885-894. [CrossRef]

13. Zhang, K.; Park, J.H. Surface localization of defects in black $\mathrm{TiO}_{2}$ : Enhancing photoactivity or reactivity. J. Phys. Chem. Lett. 2017, 8, 199-207. [CrossRef]

14. Chen, X.; Liu, L.; Huang, F. Black titanium dioxide $\left(\mathrm{TiO}_{2}\right)$ nanomaterials. Chem. Soc. Rev. 2015, 44, 1861-1885. [CrossRef]

15. Wang, G.; Wang, H.; Ling, Y.; Tang, Y.; Yang, X.; Fitzmorris, R.C.; Wang, C.; Zhang, J.Z.; Li, Y. Hydrogen-treated TiO 2 nanowire arrays for photoelectrochemical water splitting. Nano Lett. 2011, 11, 3026-3033. [CrossRef] [PubMed]

16. Danyliuk, N.; Tatarchuk, T.; Kannan, K.; Shyichuk, A. Optimization of $\mathrm{TiO}_{2}-\mathrm{P} 25$ photocatalyst dose and $\mathrm{H}_{2} \mathrm{O}_{2}$ concentration for advanced photo-oxidation using smartphone-based colorimetry. Water Sci. Technol. 2021, 84, 469-483. [CrossRef] [PubMed]

17. Tatarchuk, T.; Danyliuk, N.; Shyichuk, A.; Macyk, W.; Naushad, M. Photocatalytic degradation of dyes using rutile TiO 2 synthesized by reverse micelle and low temperature methods: Real-time monitoring of the degradation kinetics. J. Mol. Liq. 2021, 342, 117407. [CrossRef]

18. Kang, J.; Zhang, Y.; Chai, Z.; Qiu, X.; Cao, X.; Zhang, P.; Teobaldi, G.; Liu, L.; Guo, L. Amorphous domains in black titanium dioxide. Adv. Mater. 2021, 33, 2100407. [CrossRef] 
19. Wang, B.; Biesold, G.M.; Zhang, M.; Lin, Z. Amorphous inorganic semiconductors for the development of solar cell, photoelectrocatalytic and photocatalytic applications. Chem. Soc. Rev. 2021, 50, 6914-6949. [CrossRef]

20. Sun, S.; Song, P.; Cui, J.; Liang, S. Amorphous $\mathrm{TiO}_{2}$ nanostructures: Synthesis, fundamental properties and photocatalytic applications. Catal. Sci. Technol. 2019, 9, 4198-4215. [CrossRef]

21. Cheng, L.; Li, B.; Cheng, Q.; Baldwin, A.N.; Shang, Y. Investigations of indoor air quality of large department store buildings in China based on field measurements. Build. Environ. 2017, 118, 128-143. [CrossRef]

22. Chang, T.; Wang, J.; Lu, J.; Shen, Z.; Huang, Y.; Sun, J.; Xu, H.; Wang, X.; Ren, D.; Cao, J. Evaluation of indoor air pollution during decorating process and inhalation health risks in Xi'an, China: A case study. Aerosol Air Qual. Res. 2019, 19, 854-864. [CrossRef]

23. He, M.; Ji, J.; Liu, B.; Huang, $\mathrm{H}$. Reduced $\mathrm{TiO}_{2}$ with tunable oxygen vacancies for catalytic oxidation of formaldehyde at room temperature. Appl. Surf. Sci. 2019, 473, 934-942. [CrossRef]

24. Zhu, M.; Muhammad, Y.; Hu, P.; Wang, B.; Wu, Y.; Sun, X.; Tong, Z.; Zhao, Z. Enhanced interfacial contact of dopamine bridged melamine-graphene $/ \mathrm{TiO}_{2}$ nano-capsules for efficient photocatalytic degradation of gaseous formaldehyde. Appl. Catal. B Environ. 2018, 232, 182-193. [CrossRef]

25. Huang, Q.; Hu, Y.; Pei, Y.; Zhang, J.; Fu, M. In situ synthesis of $\mathrm{TiO}_{2} @ \mathrm{NH}_{2}-\mathrm{MIL}-125$ composites for use in combined adsorption and photocatalytic degradation of formaldehyde. Appl. Catal. B Environ. 2019, 259, 118106. [CrossRef]

26. Li, Y.; Chen, X.; Wang, C.; Zhang, C.; He, H. Sodium Enhances $\mathrm{Ir} / \mathrm{TiO}_{2}$ activity for catalytic oxidation of formaldehyde at ambient temperature. ACS Catal. 2018, 8, 11377-11385. [CrossRef]

27. Li, X.; Li, H.; Huang, Y.; Cao, J.; Huang, T.; Li, R.; Zhang, Q.; Lee, S.-c.; Ho, W. Exploring the photocatalytic conversion mechanism of gaseous formaldehyde degradation on $\mathrm{TiO}_{2-x}-\mathrm{O}_{\mathrm{V}}$ surface. J. Hazard. Mater. 2022, 424, 127217. [CrossRef]

28. He, F.; Jeon, W.; Choi, W. Photocatalytic air purification mimicking the self-cleaning process of the atmosphere. Nature Commun. 2021, 12, 2528. [CrossRef]

29. Wang, X.; Hong, S.; Lian, H.; Zhan, X.; Cheng, M.; Huang, Z.; Manzo, M.; Cai, L.; Nadda, A.; Le, Q.V.; et al. Photocatalytic degradation of surface-coated tourmaline-titanium dioxide for self-cleaning of formaldehyde emitted from furniture. J. Hazard. Mater. 2021, 420, 126565. [CrossRef]

30. Deng, X.-Q.; Zhu, X.; Sun, Z.-G.; Li, X.-S.; Liu, J.-L.; Shi, C.; Zhu, A.-M. Exceptional activity for photocatalytic mineralization of formaldehyde over amorphous titania nanofilms. Chem. Eng. J. 2016, 306, 1001-1009. [CrossRef]

31. Kresse, G.; Furthmüller, J. Efficiency of ab-initio total energy calculations for metals and semiconductors using a plane-wave basis set. Comp. Mater. Sci. 1996, 6, 15-50. [CrossRef]

32. Kresse, G.; Furthmüller, J. Efficient iterative schemes for ab initio total-energy calculations using a plane-wave basis set. Phys. Rev. B 1996, 54, 11169-11186. [CrossRef]

33. Perdew, J.P.; Burke, K.; Ernzerhof, M. Generalized gradient approximation made simple. Phys. Rev. Lett. 1996, 77, 3865-3868 [CrossRef]

34. Kresse, G.; Joubert, D. From ultrasoft pseudopotentials to the projector augmented-wave method. Phys. Rev. B 1999, 59, 1758-1775. [CrossRef]

35. Blöchl, P.E. Projector augmented-wave method. Phys. Rev. B 1994, 50, 17953-17979. [CrossRef] [PubMed]

36. Choudhury, B.; Choudhury, A. Oxygen vacancy and dopant concentration dependent magnetic properties of $\mathrm{Mn}^{\mathrm{d}} \mathrm{doped}$ TiO 2 nanoparticle. Curr. Appl. Phys. 2013, 13, 1025-1031. [CrossRef]

37. Huang, H.; Hou, X.; Xiao, J.; Zhao, L.; Huang, Q.; Chen, H.; Li, Y. Effect of annealing atmosphere on the performance of TiO 2 nanorod arrays in photoelectrochemical water splitting. Catal. Today 2019, 330, 189-194. [CrossRef]

38. Dutta, S.; Chattopadhyay, S.; Jana, D.; Banerjee, A.; Manik, S.; Pradhan, S.K.; Sutradhar, M.; Sarkar, A. Annealing effect on nano-ZnO powder studied from positron lifetime and optical absorption spectroscopy. J. Appl. Phys. 2006, 100, 114328. [CrossRef]

39. He, Y.; Dulub, O.; Cheng, H.; Selloni, A.; Diebold, U. Evidence for the predominance of subsurface defects on reduced anatase $\mathrm{TiO}_{2}$ (101). Phys. Rev. Lett. 2009, 102, 106105. [CrossRef]

40. Sun, W.; Li, Y.; Shi, W.; Zhao, X.; Fang, P. Formation of $\mathrm{AgI} / \mathrm{TiO}_{2}$ nanocomposite leads to excellent thermochromic reversibility and photostability. J. Mater. Chem. 2011, 21, 9263-9270. [CrossRef]

41. Liu, Y.; Chen, P.; Fan, Y.; Fan, Y.; Shi, X.; Cui, G.; Tang, B. Grey rutile $\mathrm{TiO}_{2}$ with long-term photocatalytic activity synthesized via two-step calcination. Nanomaterials 2020, 10, 920. [CrossRef]

42. Huang, J.; Yang, K.; Zhang, Z.; Yang, L.; Hirano, S. Layered perovskite $\mathrm{LiEuTiO}_{4}$ as a $0.8 \mathrm{~V}$ lithium intercalation electrode. Chem. Commun. 2017, 53, 7800-7803. [CrossRef] [PubMed]

43. Lee, J.W.; Moon, B.M.; Lee, K.M.; Kim, Y.H.; Park, H.G.; Lim, J.H.; Oh, B.Y.; Kim, B.Y.; Hwang, J.Y.; Ok, C.H.; et al. Homogeneous liquid crystal orientation on ion beam exposure $\mathrm{TiO}_{2}$ surfaces depending on an anisotropic dipole field. Liq. Cryst. 2010, 37, 279-284. [CrossRef]

44. Shi, C.; Qi, H.; Sun, Z.; Qu, K.; Huang, Z.; Li, J.; Dong, M.; Guo, Z. Carbon dot-sensitized urchin-like Ti ${ }^{3+}$ self-doped TiO 2 photocatalysts with enhanced photoredox ability for highly efficient removal of $\mathrm{Cr}^{6+}$ and RhB. J. Mater. Chem. C 2020, 8, 2238-2247. [CrossRef]

45. Li, G.; Lian, Z.; Li, X.; Xu, Y.; Wang, W.; Zhang, D.; Tian, F.; Li, H. Ionothermal synthesis of black $\mathrm{Ti}^{3+}$-doped single-crystal TiO 2 as an active photocatalyst for pollutant degradation and $\mathrm{H}_{2}$ generation. J. Mater. Chem. A 2015, 3, 3748-3756. [CrossRef]

46. Guillemot, F.; Porté, M.C.; Labrugère, C.; Baquey, C. $\mathrm{Ti}^{4+}$ to $\mathrm{Ti}^{3+}$ conversion of $\mathrm{TiO}_{2}$ uppermost layer by low-temperature vacuum annealing: Interest for titanium biomedical applications. J. Colloid Interf. Sci. 2002, 255, 75-78. [CrossRef] [PubMed] 
47. $\mathrm{Hu}, \mathrm{Z} . ; \mathrm{Yu}$, J.C.; Ming, T.; Wang, J. A wide-spectrum-responsive $\mathrm{TiO}_{2}$ photoanode for photoelectrochemical cells. Appl. Catal. B Environ. 2015, 168-169, 483-489. [CrossRef]

48. Qian, A.; Hyeon, S.E.; Seo, J.Y.; Chung, C.-H. Capacitance changes associated with cation-transport in free-standing flexible $\mathrm{Ti}_{3} \mathrm{C}_{2} \mathrm{~T}_{\mathrm{x}}(\mathrm{T}=\mathrm{O}, \mathrm{F}, \mathrm{OH}) \mathrm{MXene}$ film electrodes. Electrochim. Acta 2018, 266, 86-93. [CrossRef]

49. Qiu, H.; Ma, X.; Sun, C.; Zhao, B.; Chen, F. Surface oxygen vacancies enriched $\mathrm{Pt} / \mathrm{TiO}_{2}$ synthesized with a defect migration strategy for superior photocatalytic activity. Appl. Surf. Sci. 2020, 506, 145021. [CrossRef]

50. Xu, K.; Yang, X.; Sun, D.; Yang, X.; Zhou, Y.; Li, W.; Yang, Q.; Yang, X.; Li, R.; Feng, J. Enhanced visible-light driven photocatalytic performances over $\mathrm{LaFeO}_{3} / \mathrm{NiO}$ modified porous $\mathrm{g}-\mathrm{C}_{3} \mathrm{~N}_{4}$ nanosheets. Nano 2019, 15, 2050010. [CrossRef]

51. Gu, Y.H.; Fujimiya, Y.; Kunugita, N. Long-term exposure to gaseous formaldehyde promotes allergen-specific IgE-mediated immune responses in a murine model. Hum. Exp. Toxicol. 2008, 27, 37-43. [CrossRef]

52. Alminshid, A.H.; Abbas, M.N.; Alalwan, H.A.; Sultan, A.J.; Kadhom, M.A. Aldol condensation reaction of acetone on MgO nanoparticles surface: An in-situ drift investigation. Mol. Catal. 2021, 501, 111333. [CrossRef]

53. Li, J.; Cui, W.; Chen, P.; Dong, X.A.; Chu, Y.; Sheng, J.; Zhang, Y.; Wang, Z.; Dong, F. Unraveling the mechanism of binary channel reactions in photocatalytic formaldehyde decomposition for promoted mineralization. Appl. Catal. B Environ. 2020, $260,118130$. [CrossRef]

54. Jodłowski, P.J.; Jędrzejczyk, R.J.; Chlebda, D.; Gierada, M.; Łojewska, J. In situ spectroscopic studies of methane catalytic combustion over $\mathrm{Co}, \mathrm{Ce}$, and Pd mixed oxides deposited on a steel surface. J. Catal. 2017, 350, 1-12. [CrossRef]

55. Song, S.; Lu, C.; Wu, X.; Jiang, S.; Sun, C.; Le, Z. Strong base g- $\mathrm{C}_{3} \mathrm{~N}_{4}$ with perfect structure for photocatalytically eliminating formaldehyde under visible-light irradiation. Appl. Catal. B Environ. 2018, 227, 145-152. [CrossRef]

56. Lu, J.; Zhong, J.; Ren, Q.; Li, J.; Song, L.; Mo, S.; Zhang, M.; Chen, P.; Fu, M.; Ye, D. Construction of Cu-Ce interface for boosting toluene oxidation: Study of $\mathrm{Cu}-\mathrm{Ce}$ interaction and intermediates identified by in situ DRIFTS. Chin. Chem. Lett. 2021, 32, 3435-3439. [CrossRef]

57. Xu, P.; Xu, T.; Yu, H.; Zheng, D.; Li, X. MOF (metal-organic framework) nanomaterial for 400 ppb-concentration detectable xylene gas sensors. In Proceedings of the 2017 IEEE 30th International Conference on Micro Electro Mechanical Systems (MEMS), Las Vegas, NV, USA, 22-26 January 2017; pp. 1075-1078.

58. Hu, Z.; Yang, C.; Lv, K.; Li, X.; Li, Q.; Fan, J. Single atomic Au induced dramatic promotion of the photocatalytic activity of TiO 2 hollow microspheres. Chem. Commun. 2020, 56, 1745-1748. [CrossRef] [PubMed]

59. Jiang, B.; Zheng, J.; Qiu, S.; Wu, M.; Zhang, Q.; Yan, Z.; Xue, Q. Review on electrical discharge plasma technology for wastewater remediation. Chem. Eng. J. 2014, 236, 348-368. [CrossRef]

60. Oinuma, G.; Nayak, G.; Du, Y.; Bruggeman, P.J. Controlled plasma-Droplet interactions: A quantitative study of OH transfer in plasma-liquid interaction. Plasma Sources Sci. Technol. 2020, 29, 095002. [CrossRef] 